\title{
Effectiveness of family-centred educational interventions in the anxiety, pain and behaviours of children/adolescents and their parents' anxiety in the perioperative period: a systematic review and meta-analysis
}

Follow this and additional works at: https://www.journal.acorn.org.au/jpn

Part of the Pediatric Nursing Commons, and the Perioperative, Operating Room and Surgical Nursing Commons

(c) (i)

This work is licensed under a Creative Commons Attribution 4.0 License.

\section{Recommended Citation}

Martins Esteves, Ines; Silva Coelho, Marcia; Neves, Hugo; Pestana-Santos, Marcia; and Santos, Margarida Reis (2022) "Effectiveness of family-centred educational interventions in the anxiety, pain and behaviours of children/adolescents and their parents' anxiety in the perioperative period: a systematic review and meta-analysis," Journal of Perioperative Nursing: Vol. 35 : Iss. 1 , Article 1.

Available at: https://doi.org/10.26550/2209-1092.1153

https://www.journal.acorn.org.au/jpn/vol35/iss1/1

This Article is brought to you for free and open access by Journal of Perioperative Nursing. It has been accepted for inclusion in Journal of Perioperative Nursing by an authorized editor of Journal of Perioperative Nursing. 
Effectiveness of family-centred educational interventions in the anxiety, pain and behaviours of children/adolescents and their parents' anxiety in the perioperative period: a systematic review and meta-analysis

\section{Cover Page Footnote}

Acknowledgements This review will contribute towards a MSc in Paediatric Nursing for the first author, IE. Competing interest The authors declare no conflict of interest. 


\section{Authors}

Ines Martins Esteves

Nursing School of Porto, Portugal

Marcia Silva Coelho

Nursing School of Porto, Portugal

Hugo Neves

Health Sciences Research Unit: Nursing

(UICISA: E), Nursing School of Coimbra

(ESEnfC), Portugal

Marcia Pestana-Santos

Health Sciences Research Unit: Nursing

(UICISA: E), Nursing School of Coimbra

(ESEnfC), Portugal

\section{Margarida Reis Santos}

Nursing School of Porto; CINTESIS - Center

for Health Technology and Services

Research, Portugal

\section{Corresponding author}

Ines Martins Esteves

Nursing School of Porto, Portugal

inesmartinsesteves@gmail.com

\section{Effectiveness of family-centred educational interventions for anxiety, pain and behaviours of children and adolescents and anxiety of their parents during the perioperative journey: A systematic review and meta-analysis}

Abstract

Aim: To evaluate the effectiveness of family-centred educational interventions on the anxiety, pain and behaviours of children and adolescents (three to 19 years old) and their parents' anxiety during the perioperative journey.

Design: Systematic review of effectiveness and meta-analysis.

Data sources: MEDLINE, CINAHL, PsycINFO, Cochrane Central Register of Controlled Trials, SciELO and Sources of unpublished studies OpenGrey, Open Access Theses and Dissertations, and RCAAP - Portugal were systematically searched from January 2007 to April 2021 for available articles in English, Spanish and Portuguese.

Review methods: This review followed the methodology for systematic reviews of effectiveness from Joanna Briggs Institute (JBI). Included studies were critically appraised using JBI Critical Appraisal Checklist for Randomised Controlled Trials and JBI Critical Appraisal Checklist for Quasi-Experimental Studies. Data was synthesised through meta-analysis, using a random-effects model in the Stata Statistical Software 16.0, and narrative synthesis. Two independent reviewers performed the selection process, critical analysis, and data extraction.

Results: Twenty-eight studies (26 randomised controlled trials (RCTs) and two quasi-randomised controlled trials) were included with a total of 2516 families. In a meta-analysis of ten RCTs with 761 participants, pre-operative anxiety management was more effective in children and adolescents who received educational interventions $(\mathrm{SMD}=-1.02 ; \mathrm{SE}=0.36 ; 95 \% \mathrm{CI}[-1.73 ;-0.32])$. At the induction of anaesthesia, children and adolescents were significantly less anxious (SMD $=-1.54 ; \mathrm{SE}=0.62 ; 95 \% \mathrm{Cl}[-2.72 ;-0.36])$ and demonstrated better compliance than controls (SMD $=-1.40 ; \mathrm{SE}=0.67 ; 95 \% \mathrm{Cl}[-2.72$; -0.09]). Post-operative pain (SMD $=-0.43 ; \mathrm{SE}=0.33 ; 95 \% \mathrm{CI}[-1.05 ; 0.19])$ and pre-operative parental anxiety $(\mathrm{SMD}=-0.94 ; \mathrm{SE}=1.00 ; 95 \% \mathrm{Cl}[-2.87 ; 0.99])$ were reduced in favour of the educational interventions.

Conclusion: Family-centred educational interventions probably lead to a considerable reduction of paediatric and parental anxiety and improve paediatric behaviours at induction of anaesthesia. The evidence is very uncertain regarding the effectiveness of these interventions on post-operative paediatric maladaptive behaviours and pain intensity or parental anxiety levels at the induction of anaesthesia. 


\section{Summary of findings}

Effects of educational interventions on child and adolescent anxiety, pain and behaviours during the perioperative journey

Patient or population: Children and adolescents from three to 19 years old undergoing elective surgery.

Setting: Hospital. Intervention: Educational intervention. Comparison: Standard care / comparator.

\begin{tabular}{|c|c|c|c|c|c|c|}
\hline \multirow[b]{2}{*}{ Outcomes } & \multicolumn{2}{|c|}{$\begin{array}{l}\text { Anticipated absolute effects* } \\
\qquad(95 \% \mathrm{CI})\end{array}$} & \multirow[b]{2}{*}{$\begin{array}{l}\text { Relative } \\
\text { effect } \\
(95 \% \mathrm{Cl})\end{array}$} & \multirow[b]{2}{*}{$\begin{array}{l}\text { Number of } \\
\text { participants } \\
\text { (studies) }\end{array}$} & \multirow[b]{2}{*}{$\begin{array}{l}\text { Certainty } \\
\text { of evidence } \\
\text { (GRADE) }\end{array}$} & \multirow[b]{2}{*}{ Comments } \\
\hline & $\begin{array}{c}\text { Risk with } \\
\text { standard care/ } \\
\text { comparator }\end{array}$ & $\begin{array}{l}\text { Risk with } \\
\text { educational } \\
\text { interventions }\end{array}$ & & & & \\
\hline $\begin{array}{l}\text { Anxiety- } \\
\text { pre-operative } \\
\text { period }\end{array}$ & - & $\begin{array}{l}\text { SMD } 1.02 \text { SD lower } \\
\text { (1.73 lower to } 0.32 \\
\text { lower) }\end{array}$ & - & $\begin{array}{c}761 \\
\text { (10 RCTs) }\end{array}$ & MODERATE & $\begin{array}{l}\text { Educational interventions probably lead to a reduction in } \\
\text { pre-operative paediatric anxiety levels. Downgraded to } \\
\text { moderate certainty for serious imprecision, inconsistency and } \\
\text { publication bias. }\end{array}$ \\
\hline $\begin{array}{l}\text { Anxiety - } \\
\text { induction of } \\
\text { anaesthesia }\end{array}$ & - & $\begin{array}{l}\text { SMD } 1.54 \text { SD lower } \\
\text { (2.72 lower to } 0.36 \\
\text { lower) }\end{array}$ & - & $\begin{array}{c}598 \\
\text { (7 RCTs) }\end{array}$ & MODERATE & $\begin{array}{l}\text { Educational interventions probably lead to a reduction in } \\
\text { paediatric anxiety levels at the induction of anaesthesia. }\end{array}$ \\
\hline $\begin{array}{l}\text { Anxiety- } \\
\text { post-operative } \\
\text { period }\end{array}$ & - & $\begin{array}{l}\text { SMD } 2.33 \text { SD lower } \\
\text { (4.25 lower to } 0.40 \\
\text { lower) }\end{array}$ & - & $\begin{array}{c}301 \\
(4 \mathrm{RCTs})\end{array}$ & MODERATE & $\begin{array}{l}\text { Educational interventions probably lead to a large reduction } \\
\text { in paediatric anxiety levels post-operatively. Downgraded to } \\
\text { moderate certainty for serious imprecision, inconsistency and } \\
\text { publication bias. }\end{array}$ \\
\hline $\begin{array}{l}\text { Behaviour- } \\
\text { induction of } \\
\text { anaesthesia }\end{array}$ & - & $\begin{array}{l}\text { SMD } 1.40 \text { SD lower } \\
\text { (2.72 lower to } 0.09 \\
\text { lower) }\end{array}$ & - & $\begin{array}{c}240 \\
(2 \mathrm{RCT})\end{array}$ & MODERATE & $\begin{array}{l}\text { Educational interventions probably improve paediatric } \\
\text { behaviours at the induction of anaesthesia. Downgraded to } \\
\text { moderate certainty for serious imprecision, inconsistency and } \\
\text { publication bias. }\end{array}$ \\
\hline $\begin{array}{l}\text { Behaviour - } \\
\text { post-operative } \\
\text { period }\end{array}$ & - & $\begin{array}{l}\text { SMD } 0.12 \text { SD higher } \\
\text { (0.84 lower to } 1.09 \\
\text { higher) }\end{array}$ & - & $\begin{array}{c}172 \\
\text { (2 RCTs) }\end{array}$ & $\begin{array}{l}O \bigcirc \\
\text { VERY LOWa }\end{array}$ & $\begin{array}{l}\text { We are uncertain if family-centred educational interventions } \\
\text { reduce or increase child and adolescent post-operative } \\
\text { maladaptive behaviours. }\end{array}$ \\
\hline
\end{tabular}

Effects of educational interventions on parental anxiety during the perioperative journey

Patient or population: Parents of children and adolescents from three to 19 years old undergoing elective surgery.

Setting: Hospital. Intervention: Educational intervention. Comparison: Standard care / comparator.

\begin{tabular}{|c|c|c|c|c|c|c|}
\hline \multirow[b]{2}{*}{ Outcomes } & \multicolumn{2}{|c|}{$\begin{array}{l}\text { Anticipated absolute effects* } \\
\qquad(95 \% \mathrm{Cl})\end{array}$} & \multirow[b]{2}{*}{$\begin{array}{l}\text { Relative } \\
\text { effect ( } 95 \% \\
\text { CI) }\end{array}$} & \multirow[b]{2}{*}{$\begin{array}{l}\text { Number of } \\
\text { participants } \\
\text { (studies) }\end{array}$} & \multirow[b]{2}{*}{$\begin{array}{l}\text { Certainty } \\
\text { of evidence } \\
\text { (GRADE) }\end{array}$} & \multirow[b]{2}{*}{ Comments } \\
\hline & $\begin{array}{c}\text { Risk with } \\
\text { standard care / } \\
\text { comparator }\end{array}$ & $\begin{array}{l}\text { Risk with } \\
\text { educational } \\
\text { interventions }\end{array}$ & & & & \\
\hline $\begin{array}{l}\text { Anxiety- } \\
\text { pre-operative } \\
\text { period }\end{array}$ & - & $\begin{array}{l}\text { SMD } 0.94 \text { SD lower } \\
\text { (2.87 lower to } 0.99 \\
\text { higher) }\end{array}$ & - & $\begin{array}{c}361 \\
\text { (6 RCTs) }\end{array}$ & MODERATE & $\begin{array}{l}\text { Family-centred educational interventions probably lead } \\
\text { to a reduction in parental anxiety levels pre-operatively. } \\
\text { Downgraded to moderate certainty for serious imprecision, } \\
\text { inconsistency and publication bias. }\end{array}$ \\
\hline $\begin{array}{l}\text { Anxiety - } \\
\text { induction of } \\
\text { anaesthesia }\end{array}$ & - & $\begin{array}{l}\text { SMD } 0.55 \text { SD lower } \\
\text { (1.78 lower to } 0.67 \\
\text { higher) }\end{array}$ & - & $\begin{array}{c}376 \\
\text { (3 RCTs) }\end{array}$ & VERY LOW & $\begin{array}{l}\text { We are uncertain if family-centred educational interventions } \\
\text { reduce parental anxiety levels at the induction of } \\
\text { anaesthesia. }\end{array}$ \\
\hline $\begin{array}{l}\text { Anxiety- } \\
\text { post-operative } \\
\text { period }\end{array}$ & - & $\begin{array}{l}\text { SMD 1.64 SD lower } \\
\text { (3.05 lower to } 0.23 \\
\text { lower }\end{array}$ & - & $\begin{array}{c}203 \\
\text { (3 RCTS) }\end{array}$ & MODERATE & $\begin{array}{l}\text { Family-centred educational interventions probably lead } \\
\text { to a reduction in parental anxiety levels post-operatively. } \\
\text { Downgraded to moderate certainty for serious imprecision, } \\
\text { inconsistency and publication bias. }\end{array}$ \\
\hline
\end{tabular}




\section{Introduction}

Millions of children and adolescents undergo surgery each year. Nearly 50 to 75 per cent of them experience fear and anxiety during the perioperative period, ${ }^{2}$ feelings also reported as very common in their parents ${ }^{3-5}$. The perioperative journey comprises the pre-operative, intra-operative and post-operative periods ${ }^{6,7}$. Children are particularly vulnerable to the stress and anxiety surrounding surgery due to their cognitive development, experience and knowledge about health care..$^{8}$ Parental fear, anxiety and trauma are mirrored by parents' need for comprehensive information and advice about as well as strategies for coping with their child's surgery. ${ }^{5}$ Higher anxiety levels have been found in mothers, ${ }^{9}$ younger parents, parents of younger children, and parents whose children were undergoing their first surgery. ${ }^{10}$

High anxiety levels in children have been associated with a multitude of adverse outcomes post-operatively, 11,12 namely increased pain and necessity for higher analgesia doses and regressive behavioural disorders, ${ }^{13}$ such as nightmares, enuresis, separation anxiety and eating and emotional problems. ${ }^{14,15}$ Ultimately, the former can lead to a regression on previously gained developmental milestones such as loss of bladder control and language abilities, ${ }^{16}$ especially in younger children. 15 Parental anxiety influences how the child will respond emotionally and physically ${ }^{17}$ to the stress of surgery. ${ }^{18}$ It has been linked with increased anxiety levels in the children ${ }^{19-21}$ and post-operative maladaptive behavioural changes in the children. ${ }^{14}$ Therefore, effective management of anxiety is essential.

Proposed mechanisms for anxiety reduction comprise pharmacological and non-pharmacological strategies. ${ }^{12,22}$ The first include the administration of anxiolytic premedication $^{23}$ pre-operatively. Although beneficial, ${ }^{24,25}$ it has its side effects, and has been associated with increased hospital costs due to extended stays in recovery areas ${ }^{11}$ and delays entering the operating theatre. 2,26 Non-pharmacological strategies encompass the adoption of educational, behavioural and psychological interventions, ${ }^{12,22}$ including parental presence during induction of anaesthesia, ${ }^{27}$ and complementary medicine interventions. ${ }^{12}$

Pre-operative preparations based on educational interventions are an important component of the surgical process. ${ }^{28}$ These are cost-effective, non-invasive and carry a low risk of adverse effects. ${ }^{12}$ Family involvement is critical, as parents are a primary source of strength and support ${ }^{29}$ and know their child best. Parents play an important role as information providers to their children and are considered to be the ones children can rely on for information. ${ }^{30,31}$ Therefore, active parental involvement in the care provided can positively affect the children's health outcomes and satisfaction as well as lower hospital costs. ${ }^{32,33}$ A familycentred approach to care should be adopted when preparing the parentchild dyad for surgery in order to optimise their outcomes. ${ }^{33}$

Providing children, adolescents and parents with information about the upcoming surgery - particularly regarding the expected pre- and post-operative period, and the signs and symptoms that result from the surgical intervention - helps them manage realistic expectations about the perioperative journey. ${ }^{31,34}$ It also supports the family in developing adaptive coping mechanisms, minimising their anxiety and promoting faster recovery of their children. 2,12 In addition, detailed, developmentally appropriate ${ }^{34}$ and specific pre-procedural information such as how long the procedure will take, what will happen, who will be there and what the surgical environment is like - helps children develop a realistic representation ${ }^{35}$ of the day of surgery and, consequently, increases their cooperation throughout the perioperative

*The risk in the intervention group (and its $95 \%$ confidence interval) is based on the assumed risk in the comparison group and the relative effect of the intervention (and its $95 \% \mathrm{Cl}$ ).

$\mathrm{Cl}=$ confidence interval, SMD = standardised mean difference

GRADE Working Group grades of evidence:

- High certainty - we are very confident that the true effect lies close to that of the estimate of the effect

- Moderate certainty - we are moderately confident in the effect estimate; the true effect is likely to be close to the estimate of the effect, but there is a possibility that it is substantially different.

- Low certainty - our confidence in the effect estimate is limited; the true effect may be substantially different from the estimate of the effect.

- Very low certainty - we have very little confidence in the effect estimate; the true effect is likely to be substantially different from the estimate of the effect.

${ }^{a}$ Included studies with low number of participants. Different measurement instruments and diverse range of educational material have been used. 
period..$^{34}$ Moreover, it can affect the family's knowledge, attitudes and satisfaction, ${ }^{36}$ transforming a potentially stressful and negative experience into a formative and empowering one. ${ }^{37}$

Information provided to the family during the perioperative journey can take different forms: verbal, written or both. Books, pamphlets, guides, teaching programs or sessions (whether face-to-face, via web or audio), games for children, videos and DVDs are examples of active materials used when delivering educational interventions. ${ }^{34,38-40}$

The timing of delivering educational interventions is an important factor that must be taken into consideration. Research suggests at least five days in advance for schoolaged children and adolescents, whereas a shorter timeframe is more beneficial for younger children.12,30,34

Interventions to manage pre-operative anxiety have been previously investigated. ${ }^{37,39,41-44}$ However, many of these interventions have been tailored for and targeted at children and did not involve the family. Moreover, some have focused on exclusively controlling the children's pre-operative anxiety based on behavioural changes. Although two systematic reviews on the topic have explored the impact of technology-based ${ }^{39,43}$ preparation programs on children's and parents' anxiety, there is still the need to summarise the evidence about the effectiveness of educational interventions delivered in a family-centred approach during the perioperative journey for both children and parents.

A preliminary search of PROSPERO, MEDLINE, CINAHAL, the Cochrane Database of Systematic Reviews, and JBI Evidence Synthesis was conducted on 5 March 2021 and no current or underway systematic reviews on the topic were identified.

The objective of this systematic review is to evaluate the effectiveness of family-centred educational interventions on the anxiety, pain and behaviours of children and adolescents (three to 19 years old) and their parents' anxiety during the perioperative journey. This review did not involve primary research and therefore ethical approval was not required.

\section{Review questions}

1. What is the effectiveness of family-centred educational interventions in the anxiety, pain, and behaviours of children and adolescents (three to 19 years old) during the perioperative journey?

2. What is the effectiveness of family-centred educational interventions on parents' anxiety during the perioperative journey?

\section{Methods}

\section{Design}

This systematic review was conducted in accordance with Joanna Briggs Institute (JBI) methodology for systematic reviews of effectiveness ${ }^{45}$ and reported using the Preferred Reporting Items for Systematic Reviews and Meta-analyses (PRISMA) statement. ${ }^{46}$ This review has been registered in PROSPERO (CDR42020211574) and conducted in accordance with the a priori protocol. ${ }^{47}$

\section{Eligibility criteria}

The population of interest were parents and their children aged between three and 19 years old who were undergoing elective or scheduled surgery under general anaesthesia, regardless of the type of surgery. Parent refers to the relative or 'caregiver' - the person responsible for the child. Regarding the child or adolescent's age, the lower age limit was set at three as children from three years of age can understand simple language, are able to communicate autonomously and benefit from therapeutic play. ${ }^{48}$ Children and adolescents undergoing local or regional anaesthesia were excluded.

Studies were required to have evaluated family-centred educational interventions performed with children or adolescents and their parents during the perioperative journey. These could include any printed, written materials such as books, booklets or guides; teaching sessions or programs, whether face-to-face, via the web or audio, and games, videos, or DVDs. There were no limitations to the mode of delivery, frequency, dose or who delivered the intervention.

All family-centred educational interventions that aimed to manage the study outcomes, either applied as a single educational intervention or as a multi-component educational program (more than one of the interventions reported above), were included. Outcomes included the children and adolescents' pain, anxiety and behaviours (such as compliance at induction of anaesthesia, sleep and emotional disorders post-operatively) and anxiety in parents.

Experimental and quasi-experimental study designs including randomised controlled trials (RCTs), nonrandomised controlled trials and before-and-after studies published in Portuguese, English or Spanish were included in this review.

\section{Search strategy and study selection}

A three-step search strategy was undertaken and aimed to find both 
published and unpublished studies. First, an initial limited search of MEDLINE (PubMed) and CINAHL (EBSCOhost) was undertaken, followed by an analysis of the text words in the title and abstract and the index terms used to describe the articles. The search strategy, including all identified keywords and index terms, was adapted for each included information source and a second search was undertaken between 3 and 13 April 2021. The full search strategies are provided in supplement 1. Finally, reference lists of studies were screened for additional studies, namely, references of studies included in the systematic review and references of systematic reviews on similar topics.

Studies from 1 January 2007 to April 2021 were included. This date range was chosen as it was in 2007 that the paediatric family-centred surgical preparation became prominent and structured.11

The searched databases included MEDLINE (via PubMed), CINAHL (via EBSCOhost), PsycINFO (via EBSCOhost), Cochrane Central Register of Controlled Trials (via EBSCOhost), and SciELO. In addition, sources of unpublished studies and grey literature searched included OpenGrey, Open Access Theses and Dissertations, and Repositório Científico de Acesso Aberto em Portugal (RCAAP).

Following the search, all identified citations were collated and uploaded into EndNote X9.3 (Clarivate Analytics, PA, USA) and duplicate records were removed. A pilot test of fifty titles and abstracts was performed to improve screening strategy and avoid deviations. The remaining titles and abstracts were screened by two independent reviewers (IE, MC) for assessment against the inclusion criteria for the review. Potentially relevant studies were retrieved in full, and their citation details were imported. Authors of papers were contacted to request missing or additional data for clarification, where required. Full-text studies that did not meet the inclusion criteria were excluded, and reasons for their exclusion are provided in supplement 2. Any disagreements that arose between the reviewers were resolved through discussion or with a third reviewer (MPS).

\section{Quality appraisal}

Eligible studies were critically appraised by two independent reviewers (IE, MC) at the study level for methodological quality in the review using JBI Critical Appraisal Checklist for Randomised Controlled Trials and JBI Critical Appraisal Checklist for Quasi-Experimental Studies (non-randomised experimental studies). ${ }^{45}$ All items have three potential responses 'yes', 'unclear' and 'no', with 'yes' scoring 1, and the others 0 . Once again, any disagreements between the reviewers were resolved through discussion or with a third reviewer (MPS).

Following the critical appraisal, studies that did not reach a quality threshold (at least seven affirmative indicators for RCTs and six for quasi-experimental studies) were excluded. This decision was based on the reviewers' overall assessment of quality and risk of bias.

\section{Data extraction and synthesis}

Data were extracted using a structured form (IE, MC) which included specific information as detailed in supplement 3. When possible, studies were pooled with statistical meta-analysis using Stata Statistical Software version 16.0.49 To perform meta-analysis, studies whose results were presented as medians and respective interquartile ranges underwent conversion to mean and standard deviation estimates. ${ }^{50}$ Effect sizes, expressed as Hedges' standardised final post-intervention mean differences (for continuous data), and their 95 per cent confidence intervals, were calculated for analysis. Given the statistical heterogeneity $\left(I^{2}>50 \%\right)^{51}$ of educational interventions implementation between the included RCTs, and between-study and within-study differences, pooling of the effectiveness of these interventions was carried out using the random-effects model. ${ }^{51}$

Considering the low number of studies presenting results of the effects of educational interventions on the outcomes of the family, it was not possible to analyse the effect of each intervention independently. Subgroup analysis was performed to explore potential causes of heterogeneity and how the intervention effect varied according to the number of interventions implemented. Therefore, the authors divided the interventions into two subgroups - 'multi-component educational programs' in which more than one educational intervention was applied to the family and 'single educational interventions' in which only one intervention was delivered. The overall effect was also presented. Where there were sufficient data, meta-analysis was performed by outcome, follow-up moment and subgroup.

Sensitivity analyses were conducted to test whether the pooled effect size could be influenced by individual studies. Heterogeneity was assessed statistically using the standard $X^{2}$ and $\mathrm{I}^{2}$ tests. Funnel plots were generated to assess publication bias. Statistical tests for funnel plot asymmetry (Egger test) were performed, where appropriate. A p-value of less than 0.05 was considered significant for 
absence of publication bias. ${ }^{52}$ Where meta-analysis was not possible, the findings are presented in a narrative format.

\section{Assessing certainty in the findings}

The Grading of Recommendations, Assessment, Development and Evaluation (GRADE) ${ }^{53}$ approach for grading the certainty of evidence was followed, and a Summary of Findings (SoF) was created using GRADEPro GDT (McMaster University, ON, Canada). The outcomes reported in the SoF were anxiety, pain and behaviours for children and adolescents, and anxiety for parents.

\section{Results}

\section{Study identification and inclusion}

A total of 85 studies were retrieved for full-text review. Of these, 57 articles were excluded (see supplement 2 for a list of the articles and reasons for exclusion). The study identification is described in detail in Figure 1.

\section{Characteristics of included studies}

All included studies in this review were written in English and published between 2007 and 2021. Studies were conducted in hospital settings in Canada, ${ }^{54}$ Korea, ${ }^{55-58}$ Turkey, ${ }^{59-62}$ India, ${ }^{63,64}$ Iran,, ${ }^{65-67}$ Australia, ${ }^{68}$ Italy, ${ }^{69}$ Taiwan, ${ }^{70}$ Singapore, ${ }^{40}$ Hong Kong, ${ }^{71}$ France, ${ }^{72}$ Belgium, ${ }^{73}$ Portugal, ${ }^{74,75}$ Japan, ${ }^{76}$ Egypt, $^{77}$ Brazil $^{78,79}$ and the Netherlands ${ }^{80}$.

Sample sizes ranged from 36 to 282 participants per study. The main reasons for 'dropouts' were cancelled surgery, $54,57,70,71,76$ did not receive the allocated intervention, ${ }^{55,68}$ the participants were no longer interested, ${ }^{71}$ and failure to check outcomes' scores or inadequate data. 57,65

The majority of the participants underwent otolaryngologic surgery, $40,54,56-58,61,62,65,68,79,80$ followed by genitourinary surgery $60,63,71,74-76$ and ophthalmic surgery. ${ }^{56-58,68}$ Children were excluded from the studies if they required post-operative intensive care c5- $^{5-}$ ${ }^{58}$ or had previous surgical or post-anaesthetic complications, ${ }^{54}$ cognitive deficits or developmental disabilities, ${ }^{55-63,67-71,73-75,77-80}$ prior experience of anaesthesia/ surgery, $55-57,59,60,65,67,68,71,78,79$ history of epilepsy or seizure ${ }^{55-58,77}$ or chronic disease. ${ }^{60-62,67,70,71,77}$ Parents and guardians who did not speak the language, ${ }^{54,63,73,74,76,80}$ and were unable to complete self-report forms ${ }^{68}$ or to accompany their child ${ }^{70}$ were also excluded. The demographic and clinical variables did not significantly differ between the experimental and control groups in all studies.

The timing for the delivery of educational interventions was variable from study to study ranging from two weeks ${ }^{65}$ up to a few minutes ${ }^{65}$ before surgery. In addition, two studies did not detail when the intervention was applied ${ }^{54,61}$. The duration of the educational interventions ranged from four minutes $^{5,57}$ to one hour ${ }^{40}$. Modes of delivery included face-to-face contact with the family alone or in a group setting $^{63,71}$ (more than one family) and at the hospital or at home, tailored for the participation of the dyad, child or caregiver. All studies used direct contact with the participants to evaluate the interventions. Finally, follow-up duration varied from a minimum of the time as an inpatient (from hospital admission to discharge) to two weeks post-operatively.

Conflicts of interest were disclosed as some authors have been involved in the development of the educational material ${ }^{59,73}$ and 14 studies were funded by local ${ }^{54,66,68-71}$ and national institutions ${ }^{40,54,56,72,74,75}$ and industry (IONIX Ltd.). 55,57,58

\section{Educational interventions}

The educational interventions focused on systematic explanations about pre- and post-operative care $^{60,61,63,65,72,77-79}$ (i.e. pre-operative fasting time, personal hygiene, control of vital signs, anaesthesia and post-operative use of analgesic drugs to relieve pain), including how to prepare a child for surgery, ${ }^{60-62,72,73,76}$ types of anaesthesia, ${ }^{63,78,79}$ potential reactions of children waking up after surgery, $54,78,79$ post-operative pain management ${ }^{40,70,73}$ and strategies that parents and caregivers could use to support their child in the post-operative period.54,65 Additionally, there were educational interventions aimed at facilitating the children's adaptation to the operating room environment, through virtual reality ${ }^{55-58,80}$ and other methods, ${ }^{40,63,64,67-71,77}$ and interventions to increase knowledge about pre-operative processes undergone after admission 40,57,59-62,66,68,71-76,80 and the equipment most commonly used. 40,56-59, 62,65,67,69-71,74,77,80 Interventions also provided parents with knowledge about the equipment and procedures in the recovery room, and the roles of nurses and parents in supporting their child, 54,78,79 In many studies, children and their parents were encouraged to ask questions about the pre-operative procedures. ${ }^{55-58,60,69,71}$

Among the materials used to support the educational interventions were DVDs, ${ }^{54,65}$ videos, ${ }^{40,55,57,58,62,63,69,70,74,76,80}$ booklets, ${ }^{40,59,60,66,74,76}$ leaflets, ${ }^{64,72,78,79}$ books, ${ }^{60,61}$ one-hour of face-to-face teaching, ${ }^{40}$ verbal information, ${ }^{60}$ therapeutic play, ${ }^{59,65,67,71,77}$ demonstration of equipment using the peer modelling approach, 68 familiarisation with equipment, ${ }^{70}$ 
Records identified $(n=4500)$ from:

- MEDLINE (Pubmed) ( $n=3103)$

- CINAHL (EBSCOhost) (n=525)

- PsycINFO (EBSCOhost) $(n=333)$

- Cochrane Central Register of Controlled Trials

(EBSCOhost) $(n=249)$

- SCIELO $(n=102)$

- OpenGrey ( $n=1)$

- Open Access Thesis ( $n=32)$

- RCAAP ( $n=155)$
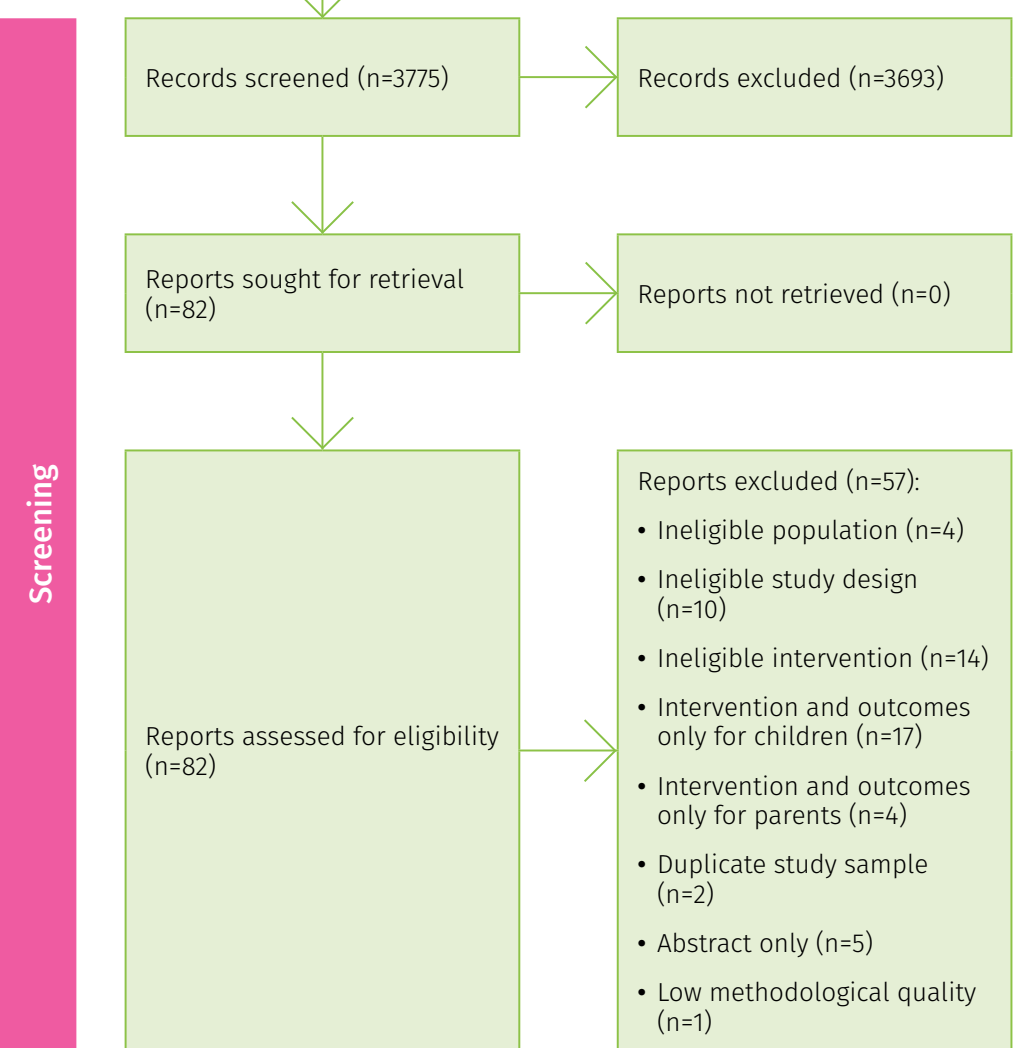

Studies included in review $(n=28)$

Reports of included studies $(n=28)$

Reports assessed for eligibility $(n=82)$

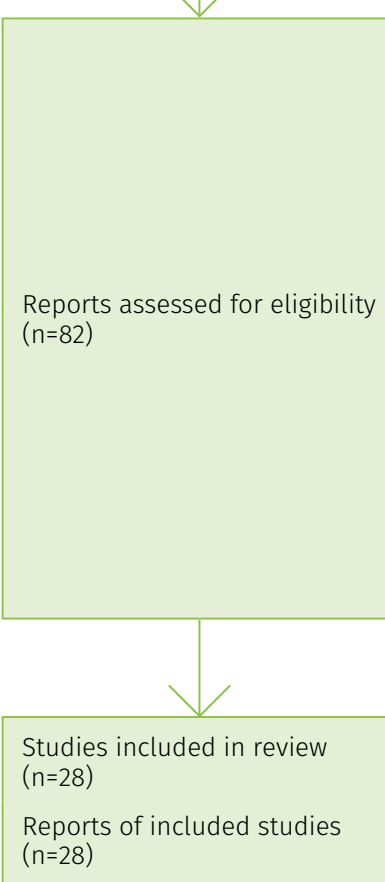

Records removed before screening:

- Duplicate records removed $(n=721)$

- Records marked as ineligible by automation tools $(n=4)$

- Records removed for other reasons $(n=0)$

Reports not retrieved $(n=0)$

Reports excluded ( $n=57)$ :

- Ineligible population $(n=4)$

- Ineligible study design

$(n=10)$

- Ineligible intervention ( $n=14)$

- Intervention and outcomes only for children $(n=17)$

- Intervention and outcomes only for parents $(n=4)$

- Duplicate study sample $(n=2)$

- Abstract only $(n=5)$

- Low methodological quality $(n=1)$

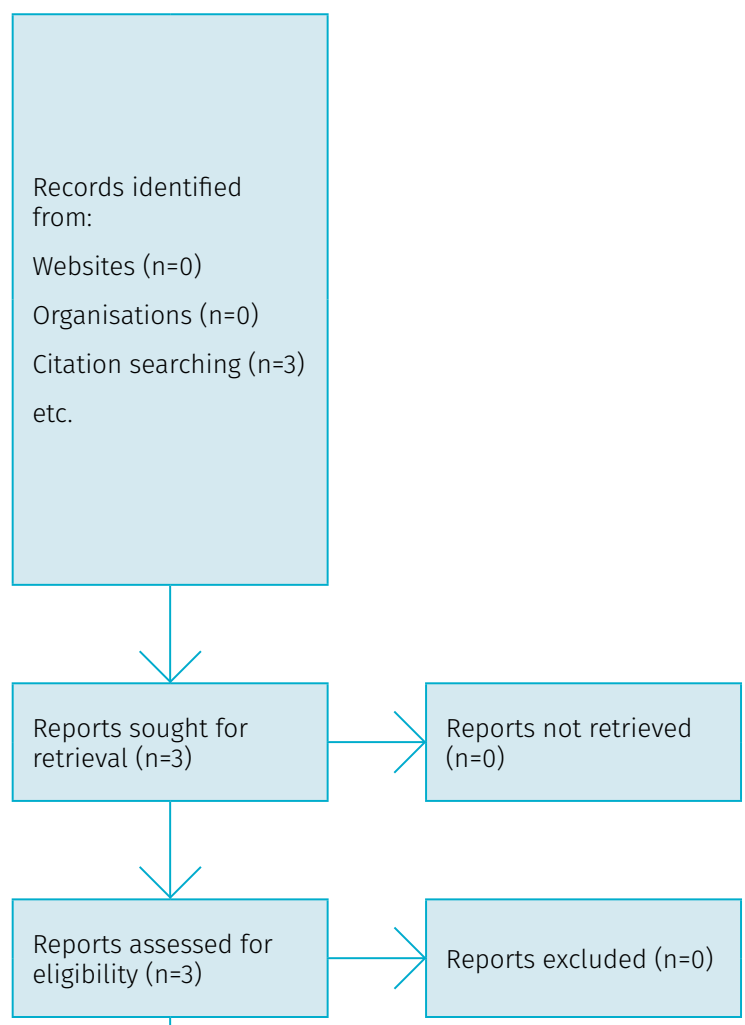

Figure 1: Search results, study selection and inclusion process ${ }^{46}$ 
tour visits, ${ }^{59,66-68,70,77}$ photo files ${ }^{64,68}$ and games..$^{56,73-75}$ Nine studies were pre-operative programs $40,59,60,64,65,67,68,70,77$ that encompassed the use of more than one material. Only one study ${ }^{55}$ reported dizziness associated with the delivery of the intervention in one participant (child).

\section{Comparators}

The comparators used in the studies were standard pre-operative care (without intervention), 40,54-57,59,60,62-64,66-73,75,77-80 intervention with non-educative materials, ${ }^{61}$ multi-component preparation programs with more than one intervention and materials used versus comparator groups (with one educational intervention), ${ }^{65}$ the noninvolvement of the family, ${ }^{58}$ absence of auxiliary materials when delivering the educational intervention, ${ }^{74}$ and the intervention's frequency of delivery. ${ }^{76}$

\section{Outcomes}

\section{Children's and adolescents' anxiety}

Regarding the outcomes and assessment tools, pre-operative anxiety in children and adolescents was assessed using the Visual Analogue Scale for anxiety (VAS-a), ${ }^{73,}$ ${ }^{80}$ FACES Rating Scale, ${ }^{76}$ the StateTrait Anxiety Inventory for Children (STAIC), ${ }^{59,64,66,72,77}$ the State-Trait Inventory form Y (STAI-Y), ${ }^{75}$ the modified Yale Pre-operative Anxiety Scale (m-YPAS), 56-58,61,62,67-69,79,80) the Hamilton Anxiety Rating Scale (HAM-A), ${ }^{63}$ the Chinese version of the State Anxiety Scale for Children (CSAS-C), ${ }^{71}$ and the Spielberger State Anxiety Scale for Children (SSAS-C). ${ }^{67}$ These instruments were measured either by the child $59,64-67,72,73,76,80$ (selfreported), the parents ${ }^{73}$ or by the study assessors ${ }^{55-58,61,62,68,69,71,78-80}$ at home (post-intervention), ${ }^{73}$ day before surgery, 59,64,77 day of surgery, ${ }^{56-58,63,66,67,69,71-73,75}$ in the holding area, ${ }^{55,61,67,79,80}$ while entering the operating room ${ }^{61,67}$ and at induction of anaesthesia. ${ }^{62,79,80}$ Additionally, some studies assessed the anxiety post-operatively. ${ }^{59,64,71}$

Seventeen studies ${ }^{56,58,59,61,63,64,66-69}$, 71-73,76-78,80 intended to investigate whether the pre-operative post-intervention anxiety levels differed for participants undergoing educational interventions from those undergoing standard care. Fourteen studies $^{56,58,63,66-69,71-73,75-78}$ found positive effects of educational interventions on reducing children's pre-operative anxiety, ten of these had statistical differences between groups ( $p \leq 0.05)$. $56,58,63,67,69,71,72,75-77$

At induction of anaesthesia, authors of five $55,57,61,62,78$ out of seven studies, ${ }^{55,57,61,62,78-80}$ reported lower anxiety levels in the participants who received educational interventions pre-operatively, with statistical differences between groups.

Six studies $59,64,68,71,76,80$ evaluated post-operative anxiety levels in children and adolescents, four of these ${ }^{64,71,76,80}$ reported lower anxiety levels in the experimental groups.

\section{Parental anxiety}

Parental anxiety was self-reported ${ }^{54,}$ 58-61,63,64,66,68,70,72-78,80 and observed ${ }^{80}$ using predominantly the StateTrait Inventory (STAI), 60,61,64,66,68,72,74,76, 77,80, the Amsterdam Pre-operative Anxiety and Information Scale (APAIS), ${ }^{70}$ the Visual Analogue Scale for Anxiety (VAS-a), ${ }^{54,80}$ the 101 Numeric Rating Scale, ${ }^{58}$ the Hamilton Anxiety Rating Scale (HAM-A), 63,67,78 and the Beck Anxiety Inventory (BAI).59 These instruments were used pre-operatively ${ }^{58-61,63,64,66,67,77,80}$ and post-operatively. .4,59,60,64 $^{\text {Parents }}$ in the experimental group showed less anxiety before surgery than the ones in the control group $60,63,66,68,75-78$. Two studies did not find significant differences between groups. ${ }^{64,66}$
Similar results were found post-operatively in four studies. ${ }^{54,59,60,64}$

\section{Children's and adolescents' behaviours}

In order to assess children's behaviours during stressful medical events like surgery, blinded observers have applied the Children's Emotional Manifestation Scale (CMES) ${ }^{70,71}$ and the Procedural Behaviour Rating Scale (PBRS). ${ }^{55,56}$ Pre-operative behaviour scores in the experimental group were three points lower than those in the control group, with children exhibiting fewer emotions at induction of anaesthesia..$^{0,71}$ Also, three ${ }^{55,56,77}$ of four studies $55,56,58,77$ reported better compliance of participants in the experimental group, with statistical significance between groups. The children's compliance during induction of anaesthesia was observer-rated using the Induction Compliance Checklist (ICC). $55,56,58,77$ High scores indicate poor behavioural compliance, whereas lower scores indicate good compliance.

The incidence of emergence delirium in children undergoing elective surgery was determined by the Paediatric Anaesthesia Emergence Delirium score (PAED) 57,70,80 and the Scoring System for Emergence Delirium. ${ }^{68}$ Among the studies, no differences were found between groups in the incidence of emergence delirium symptoms upon arrival at the recovery room or at 15 minutes after arrival.56,70,80

Post-operative behavioural disturbances such as difficulty getting to sleep, nocturnal enuresis, fear of the dark, objecting to go to bed at night and decreased appetite were investigated and assessed in five studies through the Post-Hospitalisation Behavioural Questionnaire. ${ }^{55,68,70,73,77}$ Children with high anxiety levels at induction 
Table 1: Critical appraisal results of eligible randomised controlled trials (RCTs)

\begin{tabular}{|c|c|c|c|c|c|c|c|c|c|c|c|c|c|}
\hline Study & Q1 & Q2 & Q3 & Q4 & Q5 & Q6 & Q7 & Q8 & Q9 & Q10 & Q11 & Q12 & Q13 \\
\hline Chartrand et al. $(2017)^{54}$ & Y & Y & Y & N & Y & Y & Y & Y & Y & Y & Y & Y & Y \\
\hline Ryu et al (2019)57 & Y & Y & Y & $\mathrm{N}$ & Y & $\mathrm{Y}$ & $\mathrm{Y}$ & Y & Y & Y & Y & Y & Y \\
\hline Ryu et al $(2018)^{56}$ & Y & Y & Y & N & N & Y & Y & Y & Y & Y & Y & Y & Y \\
\hline Coskunturk et al (2017)59 & Y & Y & Y & N & U & U & Y & Y & Y & Y & Y & Y & Y \\
\hline Park et al $(2019)^{58}$ & Y & Y & Y & N & Y & Y & Y & Y & Y & Y & Y & Y & Y \\
\hline Yadav et al (2020) 63 & Y & Y & Y & N & N & N & Y & Y & Y & Y & Y & Y & Y \\
\hline Faramarzi et al (2020)65 & Y & Y & Y & N & U & Y & Y & Y & Y & Y & Y & Y & Y \\
\hline Fincher et al (2012) ${ }^{68}$ & Y & Y & Y & N & N & Y & Y & Y & Y & Y & Y & Y & Y \\
\hline Liguori et al (2016)69 & Y & Y & Y & N & N & N & Y & Y & Y & Y & Y & Y & Y \\
\hline Lin et al $(2019)^{70}$ & Y & Y & Y & N & $u$ & U & Y & Y & Y & Y & Y & Y & Y \\
\hline Zhu et al $(2018)^{40}$ & Y & Y & Y & N & U & Y & Y & Y & Y & Y & Y & Y & Y \\
\hline Li et al $(2007)^{71}$ & Y & Y & Y & N & U & Y & Y & Y & Y & Y & Y & Y & Y \\
\hline Kassai et al (2016) & Y & Y & Y & N & N & N & Y & Y & Y & Y & Y & Y & Y \\
\hline Aydin et al (2021) 61 & Y & Y & Y & N & $u$ & Y & Y & Y & Y & Y & Y & Y & Y \\
\hline Matthyssens et al $(2020)^{73}$ & Y & Y & Y & N & Y & $u$ & Y & Y & Y & Y & Y & Y & Y \\
\hline Tabrizi et al (2015) 66 & Y & Y & Y & u & U & U & Y & N & Y & Y & Y & Y & Y \\
\hline Batuman et al (2015) ${ }^{62}$ & Y & Y & Y & N & U & Y & Y & Y & Y & Y & Y & Y & Y \\
\hline Fernandes et al (2014) & Y & N & Y & N & U & U & Y & Y & Y & Y & Y & Y & Y \\
\hline Ryu et al $(2017)^{55}$ & Y & Y & Y & N & U & Y & Y & Y & Y & Y & Y & Y & Y \\
\hline Wakimizu et al (2009) & Y & Y & Y & Y & Y & U & Y & Y & Y & Y & Y & Y & Y \\
\hline Vaezzadeh et al (2011) $)^{67}$ & Y & Y & Y & N & U & Y & Y & Y & Y & Y & Y & Y & Y \\
\hline Cumino et al $(2013)^{78}$ & Y & Y & Y & u & U & U & Y & Y & Y & Y & Y & Y & Y \\
\hline Kumar et al (2019) & Y & Y & Y & N & N & N & Y & Y & Y & Y & Y & Y & Y \\
\hline Cumino et al (2017) ${ }^{79}$ & Y & Y & Y & N & U & U & Y & Y & Y & Y & Y & Y & Y \\
\hline Fernandes et al $(2015)^{75}$ & Y & Y & Y & u & u & U & Y & Y & Y & Y & Y & Y & Y \\
\hline Eijlers et al (2019)80 & Y & Y & Y & N & Y & Y & Y & Y & Y & Y & Y & Y & Y \\
\hline Total \% & 100 & 96 & 100 & 3 & 23 & 46 & 100 & 96 & 100 & 100 & 100 & 100 & 100 \\
\hline
\end{tabular}

$\mathrm{Y}=$ yes, $\mathrm{N}=$ no, $\mathrm{U}=$ unclear; JBI critical appraisal checklist for randomised controlled trials: $\mathrm{Q1}$ = Was true randomisation used for assignment of participants to treatment groups? Q2 = Was allocation to treatment groups concealed? Q3 = Were treatment groups similar at baseline? Q4 = Were participants blind to treatment assignment? Q5 = Were those delivering treatment blind to treatment assignment? Q6 = Were outcome assessors blind to treatment assignment? Q7 = Were treatment groups treated identically other than the intervention of interest? Q8 = Was follow-up complete and, if not, were strategies to address incomplete follow-up utilised? Q9 = Were participants analysed in the groups to which they were randomised? Q10 = Were outcomes measured in the same way for treatment groups? Q11 = Were outcomes measured in a reliable way? Q12 = Was appropriate statistical analysis used? Q13 = Was the trial design appropriate, and any deviations from the standard RCT design (individual randomisation, parallel groups) accounted for in the conduct and analysis of the trial? 
Table 2: Critical appraisal results of eligible quasi-randomised controlled trials (quasi-RCTs)

\begin{tabular}{|l|c|c|c|c|c|c|c|c|c|}
\hline Study & Q1 & Q2 & Q3 & Q4 & Q5 & Q6 & Q7 & Q8 & Q9 \\
\hline Bartik et al (2018)60 & Y & Y & Y & Y & Y & Y & Y & Y & Y \\
\hline Sabaq et al (2012) & Y & Y & Y & Y & Y & Y & Y & Y & Y \\
\hline Total \% & 100 & 100 & 100 & 100 & 100 & 100 & 100 & 100 & 100 \\
\hline
\end{tabular}

$\mathrm{Y}=$ yes, $\mathrm{N}=$ no, $\mathrm{U}=$ unclear; JBI critical appraisal checklist for quasi-experimental studies: $\mathrm{Q} 1=$ Is it clear in the study what is the 'cause' and what is the 'effect' (i.e. there is no confusion about which variable comes first)? Q2 = Were the participants included in any comparisons similar? Q3 = Were the participants included in any comparisons receiving similar treatment/care, other than the exposure or intervention of interest? Q4 = Was there a control group? Q5 = Were there multiple measurements of the outcome both pre and post the intervention/exposure? Q6 = Was follow up complete and, if not, were differences between groups in terms of their follow up adequately described and analysed? $\mathbf{Q 7}=$ Were the outcomes of participants included in any comparisons measured in the same way? Q8 = Were outcomes measured in a reliable way? Q9 = Was appropriate analysis used?

of anaesthesia ${ }^{62}$ reported higher ratios of post-operative behaviours one week after surgery. One study ${ }^{77}$ reported more problems falling asleep, staying asleep and waking up crying in the control group as compared with children in the experimental group. The remaining studies ${ }^{68,70,73}$ did not find significant differences between groups but reported a higher incidence of these behaviours in those who received the educational interventions pre-operatively.

\section{Children's and adolescents' post-operative pain}

Eight studies $40,54,64,65,68,7,7,7,80$ explored whether the post-operative pain scores differed for participants undergoing educational interventions from those undergoing standard care. Five found lower pre-operative pain scores in the experimental group in the recovery room ${ }^{65}$ and post-operatively. ${ }^{54,64,65,68,71}$ Of these, three showed statistical differences between groups $(p \leq 0.05)$. 54,64,68 Only one study ${ }^{73}$ has reported a significant correlation between anxiety levels and pain one week post-operatively $(r=0.512 ; p=0.00)$.

Children's post-operative pain $40,54,6,65,6,6,7,7,3,80$ was measured using the Visual Analogue Scale for pain (VAS-p), ${ }^{65,77}$ Wong-Baker Scale, ${ }^{64}$ the revised Faces Pain
Scale (FPS-r), 68,80 the Face, Legs, Activity, Cry, Consolability (FLACC) scale $^{68,80}$, the Numeric Rating Scale ${ }^{40}$ and the Modified Children's Hospital of Eastern Ontario Pain Score (mCHEOPS). ${ }^{54}$ These reliable and validated instruments were self-assessed by the child, ${ }^{71,73,80}$ parents ${ }^{40,73,80}$ or assessors of the study ${ }^{54,65,68,80}$ at different time points - in the recovery room, ${ }^{54,65,80}$ at the day-care surgery unit after recovery, ${ }^{54,64}$ and up to two weeks post-operatively. ${ }^{40,65}$ One study ${ }^{71}$ did not detail when the post-operative pain was assessed.

\section{Quality appraisal}

The current systematic review included 28 studies, 26 RCTs and two quasi-experimental studies (quasi-RCTs). All the included RCTs answered 'yes' to eight of 13 checklist quality criteria - Q1, Q3, Q7, Q9-Q13 (see Table 1). The two quasi-RCTs answered 'yes' to all checklist criteria (see Table 2). This assessment identified potential methodological weaknesses and sources of bias in the review. First, only one RCT ${ }^{76}$ provided information on participants' blinding to treatment assignment; whereas the remaining studies, due to the nature of the intervention, failed to provide information about this criterion. Similarly, studies have failed to guarantee blinding to treatment assignment for personnel delivering treatment $t^{55,56,59-63,65-72,7,7,7,7,7,79}$ and assessing the outcomes. $59,60,63,64,6,6,69,7,7,72-76,78,79$ This could be explained by the complexity of concealing group allocation, both from participants and those delivering the treatment, when specific interventions such as educational interventions are being used. Also, authors of one study argued the impossibility of organising blinding of outcome assessment due to the lack of funding. ${ }^{2}$

Even though the authors have conducted the appropriate statistical analysis, five studies ${ }^{70,72-74,76}$ did not report sufficient data to perform meta-analysis on any outcome. Moreover, meta-analysis of quasiRCTs was not performed. Therefore, these results as well as the results from all quasi-RCTs ${ }^{60,77}$ are presented in a narrative format.

\section{Review findings}

\section{Effect of family-centred} educational interventions on children's and adolescents' anxiety

Pooled analysis of ten RCTS ${ }^{56,58,59,63,64,66,67,69,7,7,75}$ involving 761 participants favoured the implementation of educational interventions (Figure 2). Moderatecertainty evidence indicates 
that educational interventions probably lead to a large reduction in pre-operative paediatric anxiety levels (SMD = -1.02; SE =0.36; 95\% $\mathrm{Cl}[-1.73 ;-0.32] ; p=0.02)$. In addition, children and adolescents who participated in a 'single educational Intervention' (SEI) expressed lower anxiety scores than children enrolled in a 'multi-component educational program' (M-CEP) (SMD $=-1.29 ; \mathrm{SE}=0.48 ; \mathrm{p}=0.04 ; \mathrm{SMD}_{\mathrm{M}-\mathrm{CEP}}=$ -0.43; $S E=0.40 ; p=0.39$ ).

However, there was high statistical heterogeneity across the individual studies of both subgroups $\left(1^{2}=\right.$ $84.75 \%$ and $\mathrm{I}^{2}=95.41 \%$, respectively). Publication bias was apparent from the funnel plot and Egger's test ( $p=$ 0.58) (see Figure 3). Sensitivity analysis was performed by excluding the lowest quality study score ${ }^{66}$

$\left(S_{M D} D_{M-C E P}=-0.38 ; S E=0.65 ; p=0.63 ; 1^{2}\right.$ $=95.1 \% ; \mathrm{SMD}_{\text {overall }}=-1.08 ; \mathrm{SE}=0.40 ; \mathrm{p}=$ $0.028 ; 12=95.50 \%$ ) and the study that used a different comparator ${ }^{58}$ $\left(\mathrm{SMD}_{\text {overall }}=-0.92 ; \mathrm{SE}=0.39\right.$; $\left.p=0.047 ; I^{2}=95.00 \%\right)$. The result did not change significantly.

In this review, we have considered the induction of anaesthesia in all studies that reported paediatric anxiety from the holding area up to entering the operating theatre. Pooled analysis of seven RCTS $^{55,57,61,62,78-80}$ including 598 participants favoured the use of educational interventions. Moderatecertainty evidence indicates that educational interventions probably lead to a large reduction in paediatric anxiety scores at induction of anaesthesia $(\mathrm{SMD}=-1.54 ; \mathrm{SE}=0.62$; 95\% Cl $[-2.72 ;-0.36] ; p=0.046 ; 1^{2}=$ 97.52\%; Egger's test $=0.009)($ see Figure 4).

Post-operatively, even though four studies $59,64,68,71$ have investigated children's and adolescents' anxiety, only three RCTs, 59,64,71 with 301 participants, were included for meta-analysis. Moderate-certainty evidence indicates that educational interventions probably largely reduce post-operative anxiety scores (SMD = -2.33; SE $=0.98 ; 95 \% \mathrm{Cl}[-4.25 ;-0.40] ; \mathrm{p}$ $\left.=0.14 ;\left.\right|^{2}=95.92 \%\right)$ (see Figure 5).

According to the results of Egger's test, supported by the funnel plot, there was publication bias in this outcome $(p=0.18)$ (see Table 3$)$.

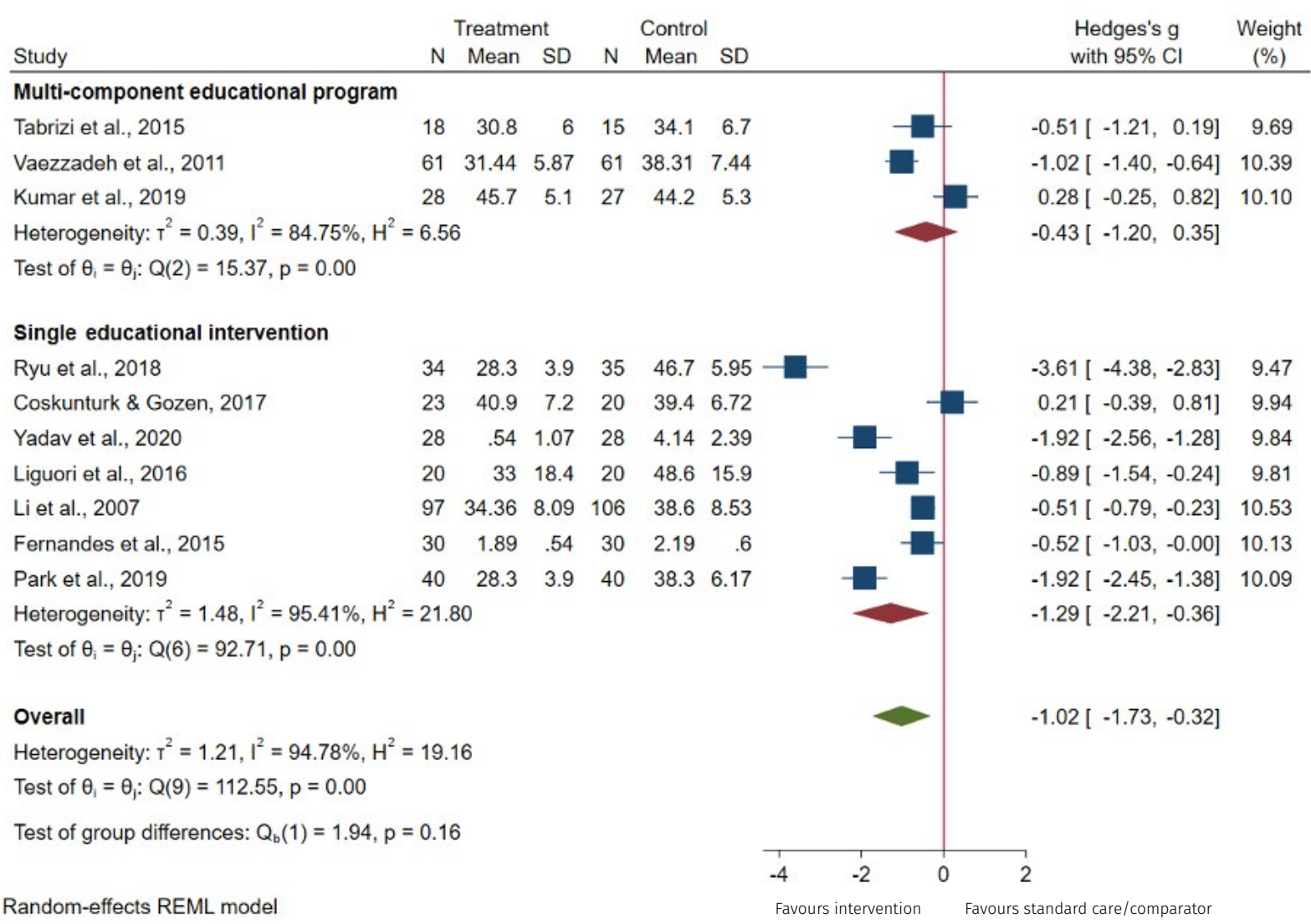

Figure 2: Pre-operative anxiety in children and adolescents - forest plot

Forest plot showing effect sizes (Hedges' g) and 95\% confidence interval (Cl) with a pooled subgroup analysis (random-effects model) of the multi-component educational programs and single educational intervention's studies. 
Effect of family-centred educational interventions on children's and adolescents' behaviour

At the induction of anaesthesia, pooled analysis of two studies, ${ }^{56,71}$ with a total sample size of 272 children, favoured the use of educational interventions $(S M D=$ -1.40; SE $=0.67 ; 95 \% \mathrm{Cl}[-2.72 ;-0.09] ; \mathrm{p}$ $=0.28 ; 1^{2}=93.75 \%$ ) (see Figure 6). Moderate-certainty evidence indicates that educational interventions probably lead to a large improvement of paediatric behaviour at this time point.

Two RCTs ${ }^{54,68}$ of 172 children and adolescents were included for meta-analysis to assess the effectiveness of educational interventions on children's and adolescents' post-operative maladaptive behaviours. The findings showed a slightly higher incidence of post-operative behavioural disturbance in the study groups than in the control groups (SMD = 0.12; SE = 0.15; 95\% Cl [-0.84; 1.09];

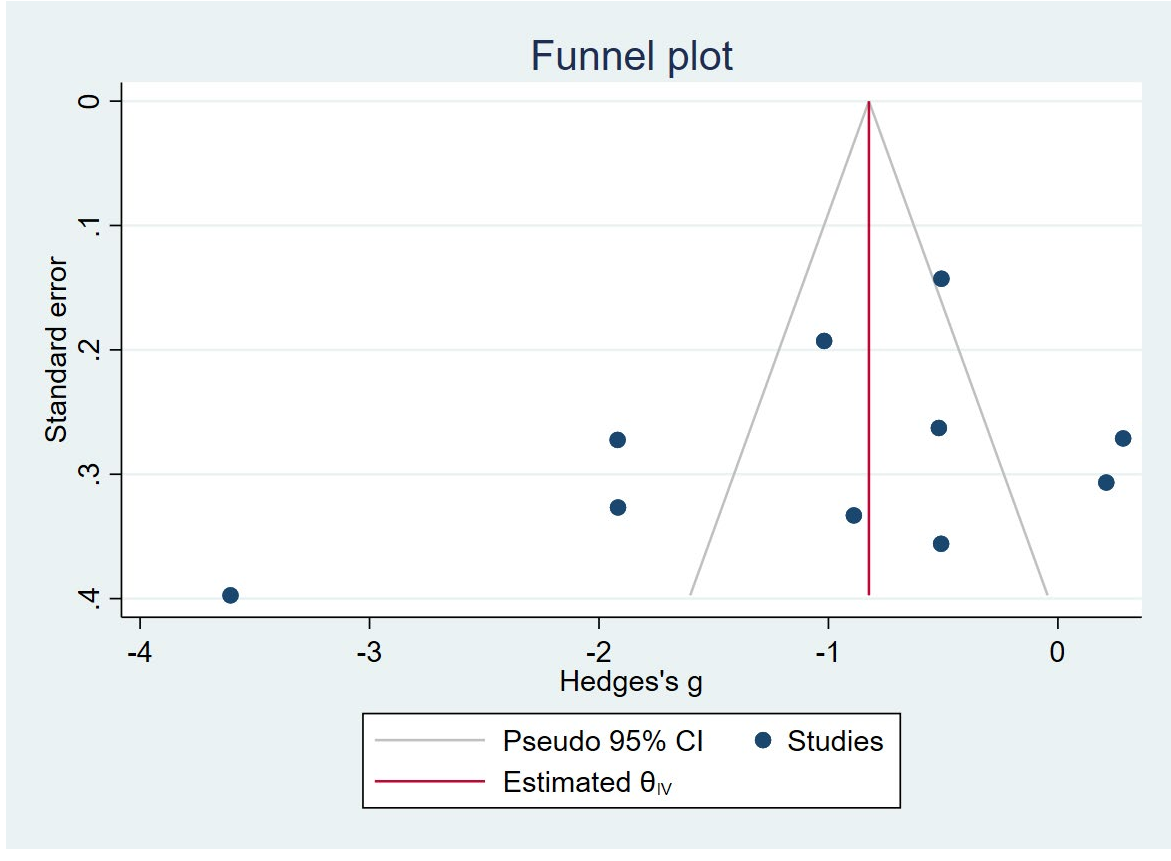

Figure 3: Pre-operative anxiety in children and adolescents - funnel plot $\left.p=0.56 ; 1^{2}=100 \%\right)$ (see Figure 7).

However, the shallow quality of the evidence does not allow us to state if educational interventions either improve or exacerbate post-operative behavioural disturbances.

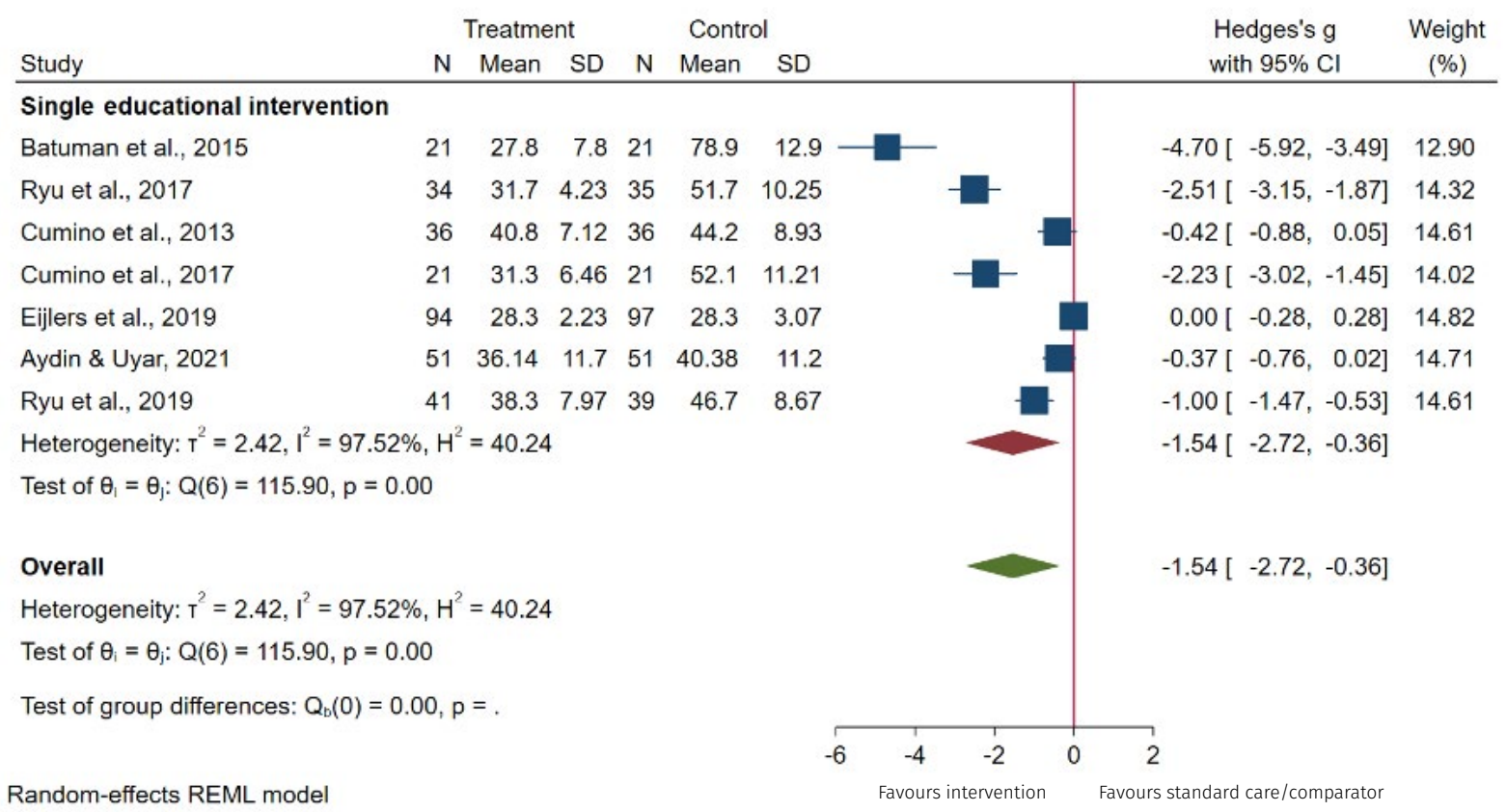

Figure 4: Anxiety at induction of anaesthesia in children and adolescents

Forest plot showing effect sizes (Hedges' g) and 95\% confidence interval ( $\mathrm{Cl}$ ) with a pooled analysis (random-effects model) of the single educational interventions' studies. 


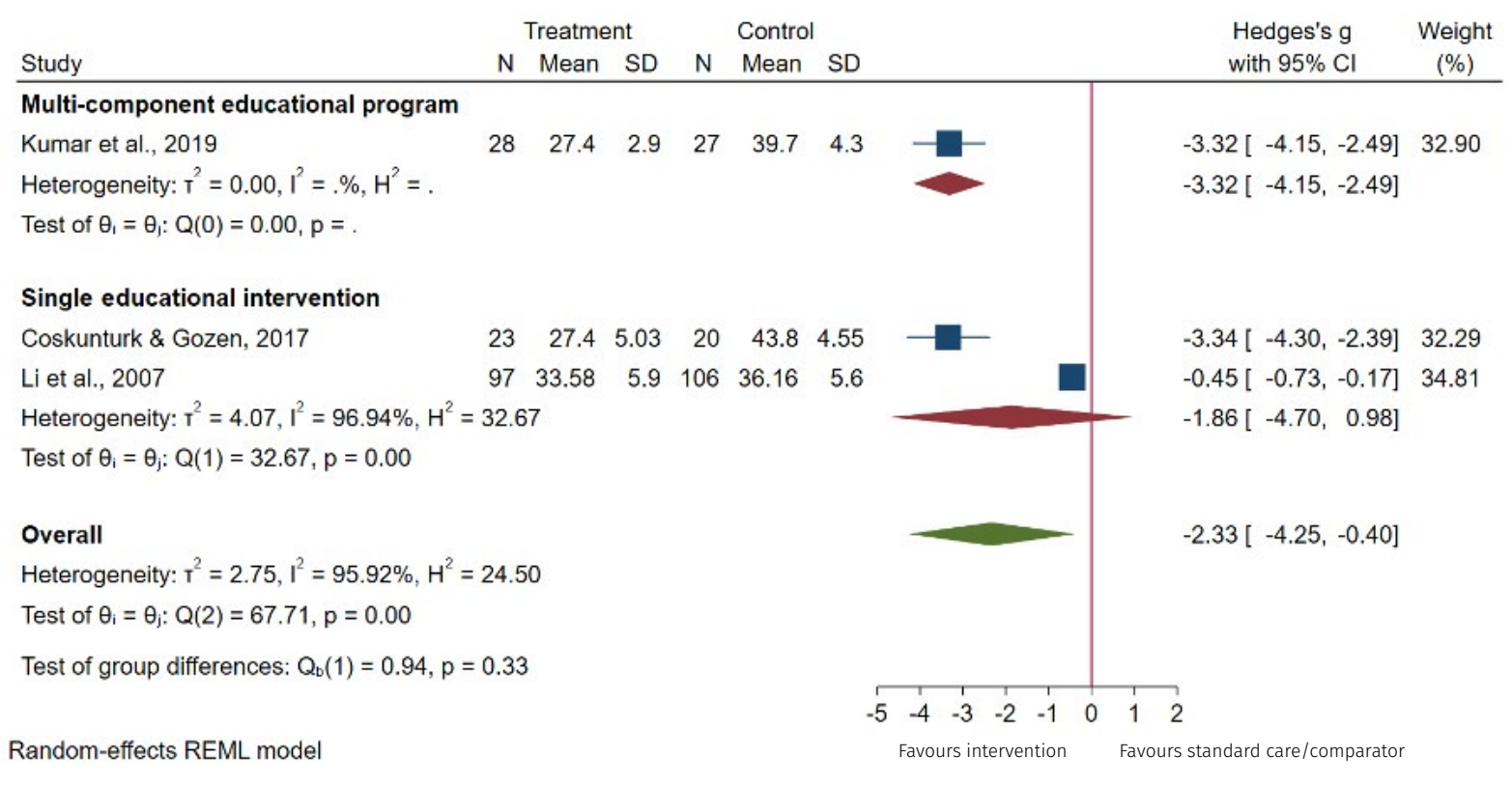

Figure 5: Post-operative anxiety in children and adolescents

Forest plot showing effect sizes (Hedges' g) and 95\% confidence interval ( $\mathrm{Cl}$ ) with a pooled analysis (random-effects model) of the multi-component educational program and single educational intervention's studies.

Table 3: Post-operative children and adolescents' anxiety - Egger's regression-based test

\begin{tabular}{|c|c|c|c|c|c|c|c|}
\hline & \multirow[b]{2}{*}{ Parameter } & \multirow[b]{2}{*}{ Coefficient } & \multirow[b]{2}{*}{ Std. Error } & \multirow[b]{2}{*}{$\mathrm{t}$} & \multirow[b]{2}{*}{ Sig. (2-tailed) } & \multicolumn{2}{|c|}{ 95\% Confidence Interval } \\
\hline & & & & & & Lower & Upper \\
\hline \multirow[t]{2}{*}{ Overall } & (Intercept) & 0.86 & 0.25 & 3.39 & .18 & -2.36 & 4.08 \\
\hline & $\mathrm{SE}^{\mathrm{C}}$ & -9.22 & 1.13 & -8.19 & .08 & -23.52 & 5.09 \\
\hline
\end{tabular}

Random effects meta-regression with the truncated Knapp-Hartung SE adjustment

c. standard error of effect size.

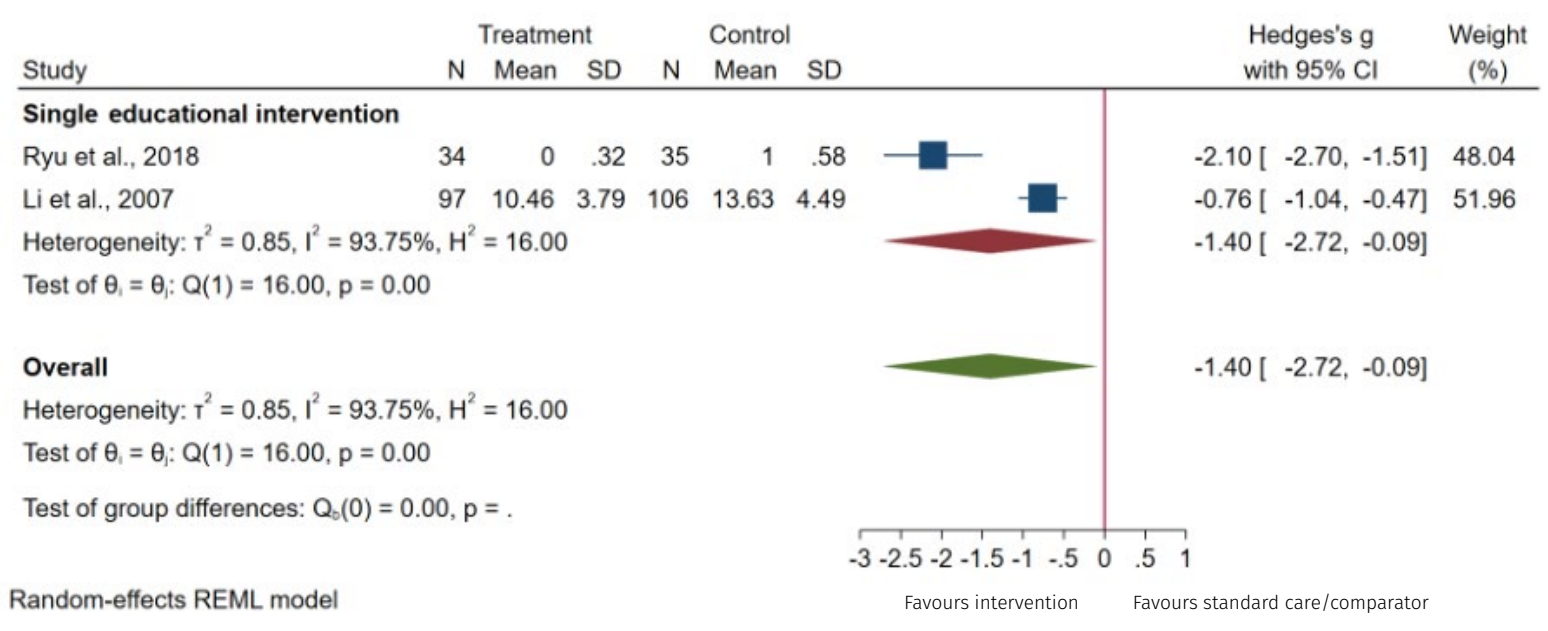

Figure 6: Behaviour at induction of anaesthesia in children and adolescents

Forest plot showing effect sizes (Hedges' g) and 95\% confidence interval (Cl) with a pooled analysis (random-effects model) of single educational interventions' studies. 


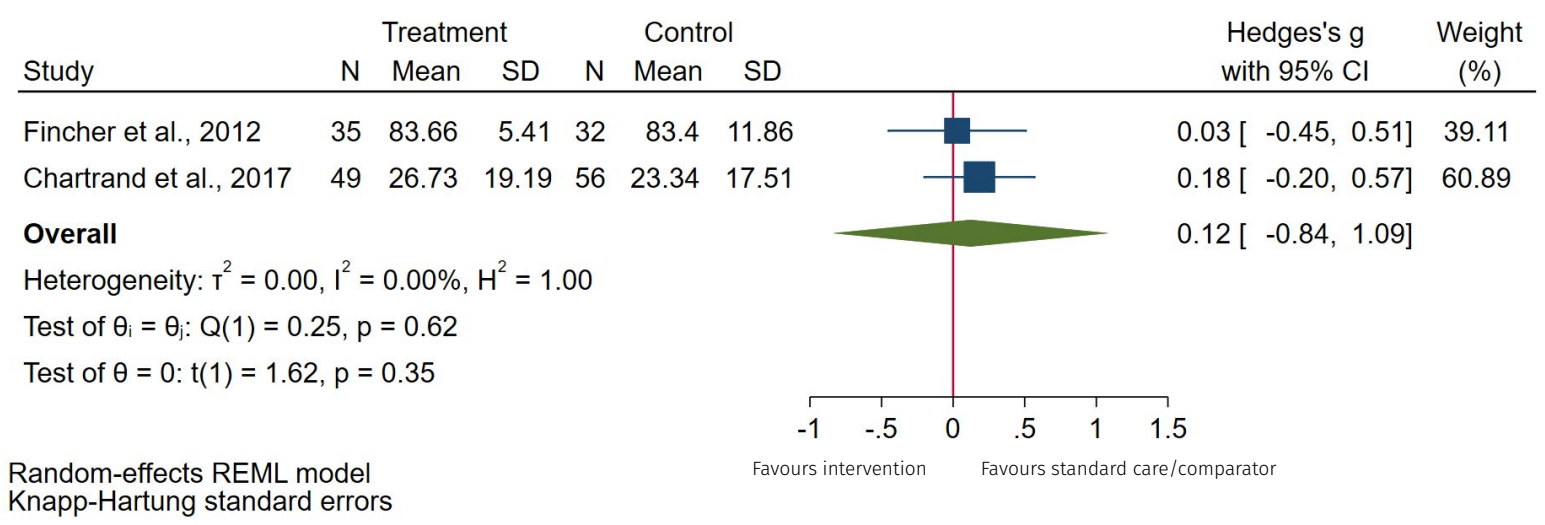

Figure 7: Post-operative behaviour in children and adolescents

Forest plot showing effect sizes (Hedges' g) and 95\% confidence interval (Cl) with a pooled analysis (random-effects model) of the single educational interventions' studies.

\section{Effect of family-centred}

\section{educational interventions on} children's and adolescents' pain

Four RCTs, 40,64,65,71 with a total sample size of 599 participants, were included in the pooled subgroup analysis to examine the impact of educational interventions on children's post-operative pain (see
Figure 8). Overall results suggest nonsignificant differences in post-operative pain scores among participants of both groups (SMD = -0.43; SE = 0.33; 95\% Cl [-1.05; 0.19] $p=$ 0.28). In addition, the heterogeneity across the individual studies was high $\left(1^{2}=92.17 \%\right)$ and publication bias was present ( $p=0.31$, Egger's regression test).

\section{Effect of family-centred educational interventions on parental anxiety}

A meta-analysis of six RCTs, 59,61,63,64,66,78 with 361 parents, was performed. Moderate-certainty evidence indicates that educational interventions probably lead to a large reduction in pre-operative parental

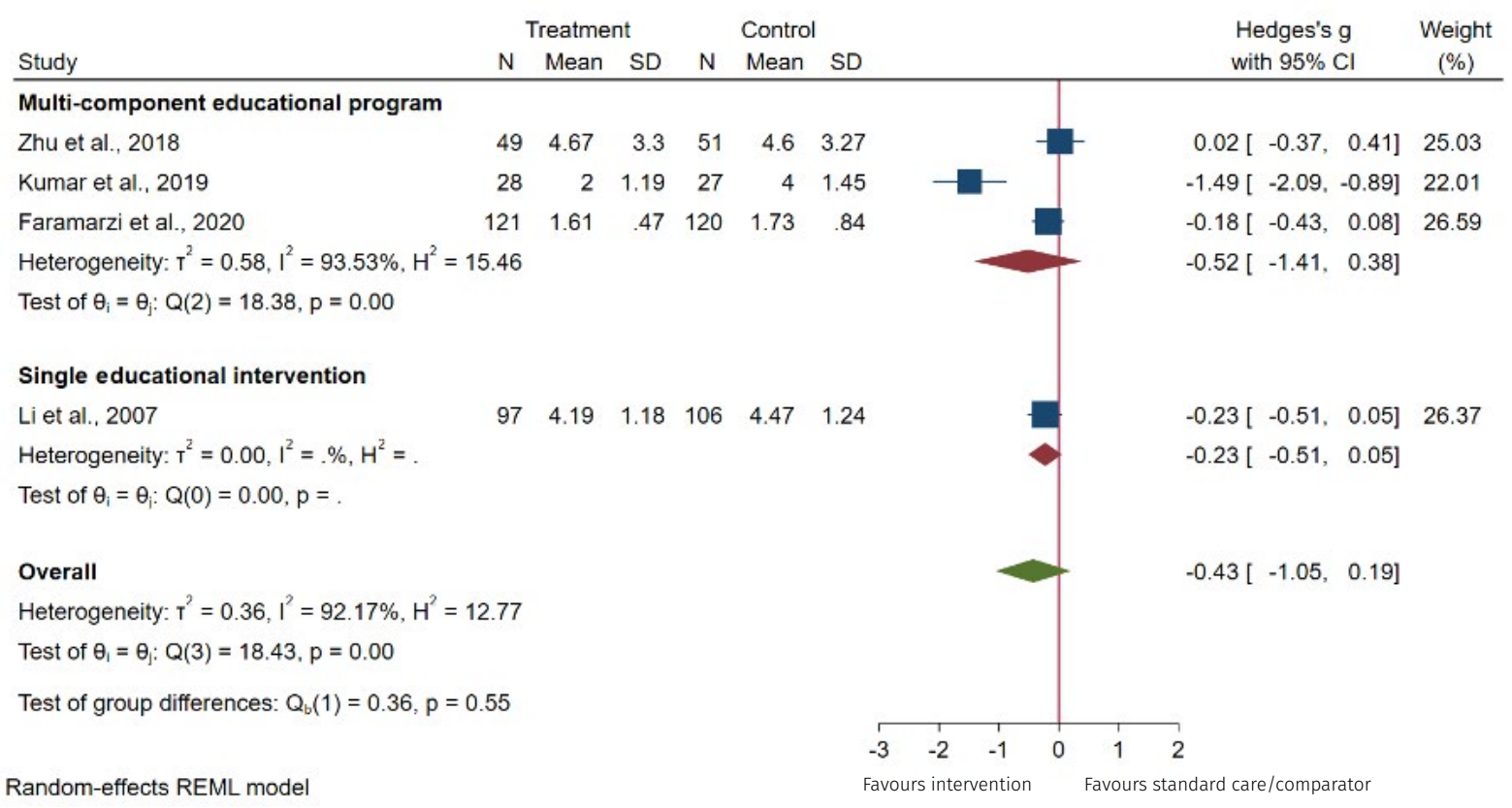

Figure 8: Post-operative pain in children and adolescents

Forest plot showing effect sizes (Hedges' g) and 95\% confidence interval (CI) with a pooled subgroup analysis (random-effects model) of the multi-component educational program and single educational interventions' studies. 


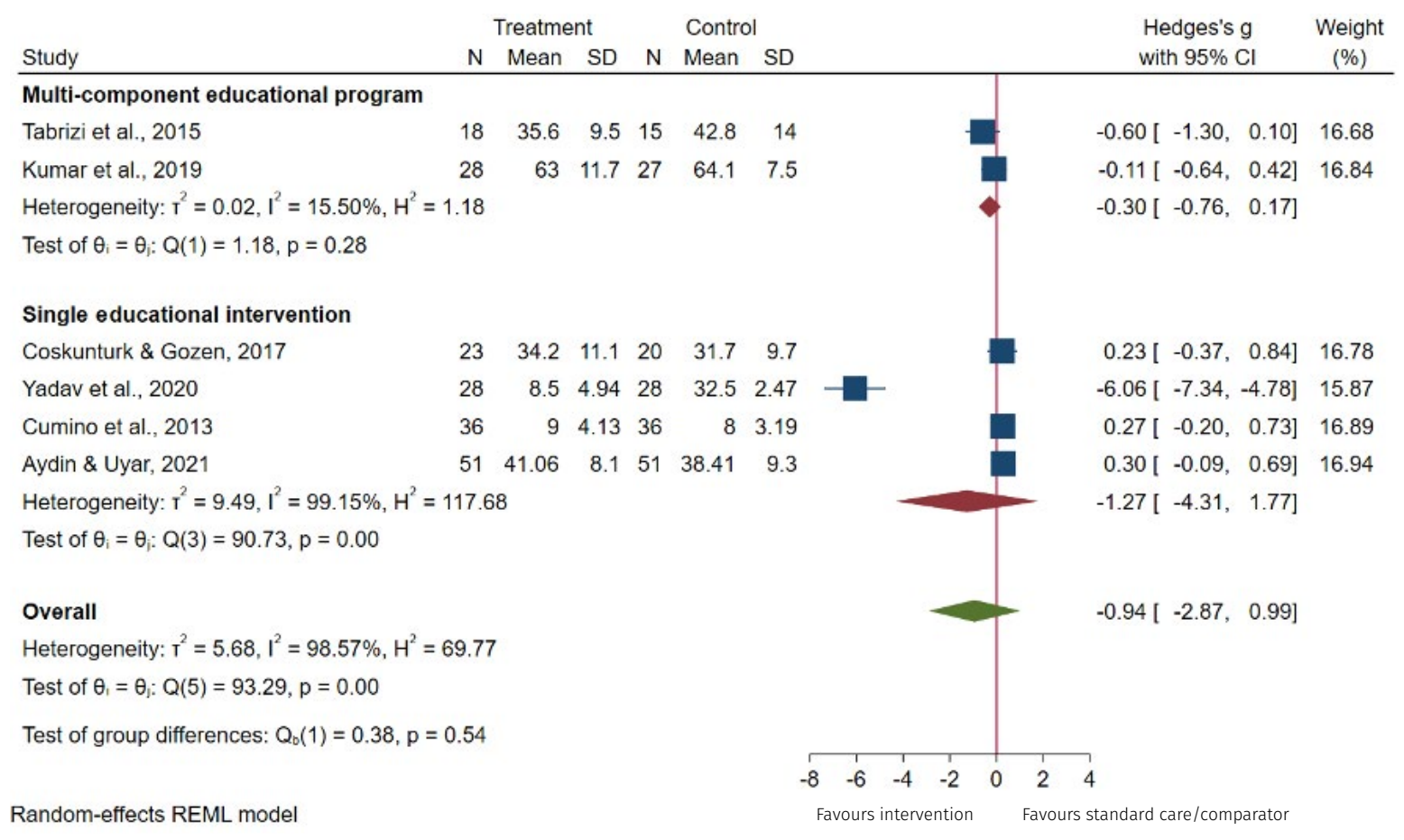

Figure 9: Pre-operative parental anxiety

Forest plot showing effect sizes (Hedges' g) and 95\% confidence interval (Cl) with a pooled subgroup analysis (random-effects model) of the multi-component educational program and single educational intervention's studies.

anxiety levels $(\mathrm{SMD}=-0.94 ; \mathrm{SE}=1.00$; 95\% Cl [-2.87; 0.99]; $p=0.39$ ) (see Figure 9).

Statistical heterogeneity was low in the multi-component educational program subgroup $\left(1^{2}=15.50 \%\right)$ and substantial in the single-educational intervention subgroup $\left(1^{2}=99.15 \%\right)$. Egger's test was statistically significant for absence of publication bias $(p=0.007)$ (see Figure 10).

At induction of anaesthesia, three $\mathrm{RCTS}^{54,58,80}$ were included for metaanalysis, with a total sample size of 376 parents (see Figure 11).

The evidence is very uncertain regarding the benefits of educational interventions on parental anxiety levels at this time point. In addition, the meta-analysis results (SMD = $-0.55 ; \mathrm{SE}=0.63 ; \mathrm{p}=0.47 ; \mathrm{I}^{2}=96.69 \%$ ) were mainly favoured by one study, ${ }^{58}$ showing the serious inconsistency across the studies. There was publication bias according to the funnel plot and Egger's regressionbased test ( $p=0.24)$.
A meta-analysis of three RCTs, 54,59,64 involving 203 parents, evaluated the impact of educational interventions on post-operative parental anxiety

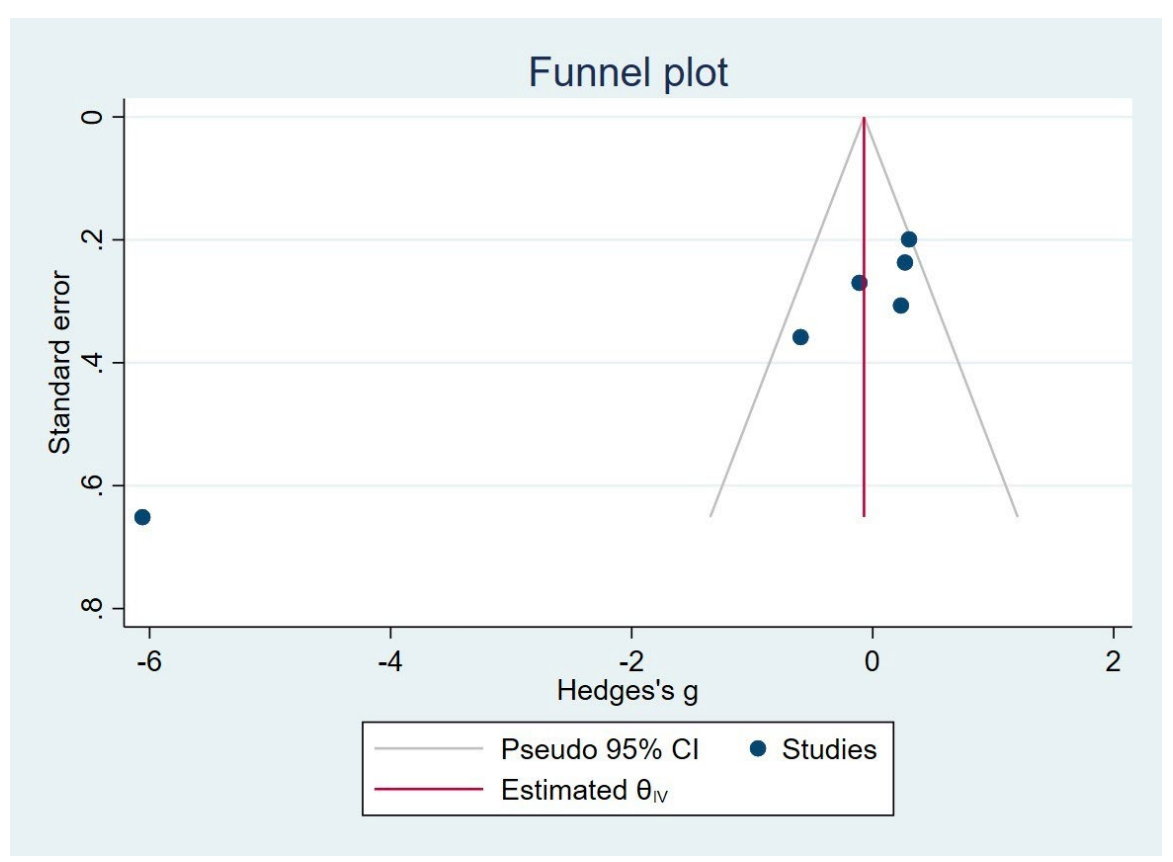

Figure 10: Pre-operative parental anxiety - funnel plot 


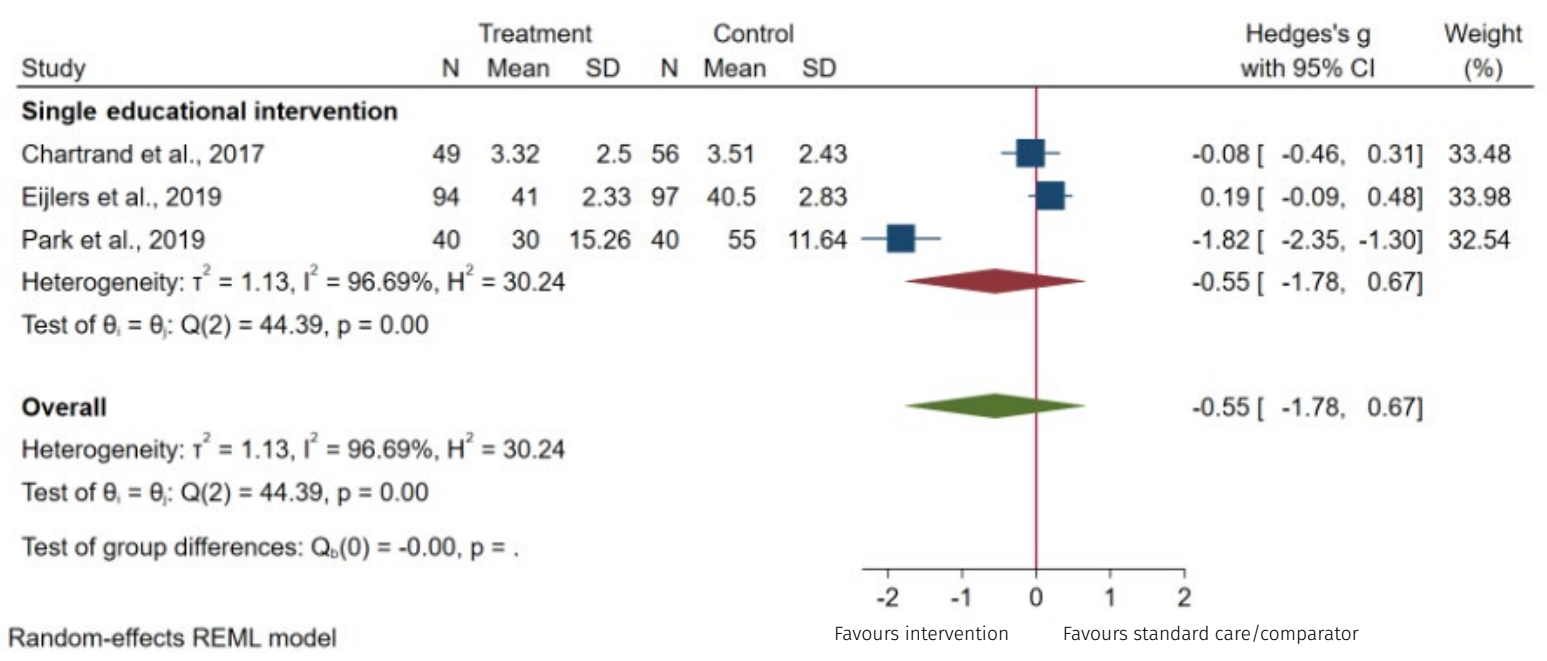

Figure 11: Parental anxiety at induction of anaesthesia

Forest plot showing effect sizes (Hedges' g) and 95\% confidence interval ( $\mathrm{Cl}$ ) with a pooled analysis (random-effects model) of the single educational intervention's studies.

(see Figure 12). Moderate-certainty evidence indicates that educational interventions probably lead to a large reduction in post-operative parental anxiety levels (SMD $=-1.64$; $\mathrm{SE}=0.72 ; 95 \% \mathrm{Cl}[-3.05 ;-0.23] ; \mathrm{p}=$ 0.15). Nevertheless, the high heterogeneity $\left(1^{2}=93.75 \%\right.$; Figure 12) and the publication bias ( $p=0.11$; Egger's test) require these results to be carefully interpreted.

Sensitivity analysis was performed for paediatric and parental anxiety levels in the pre-operative period and at the induction of anaesthesia. Studies that used other comparators than standard care co, $61,65,74$ were individually excluded; the overall heterogeneity among the studies remained high $\left(I^{2}>80.00 \%\right)$.

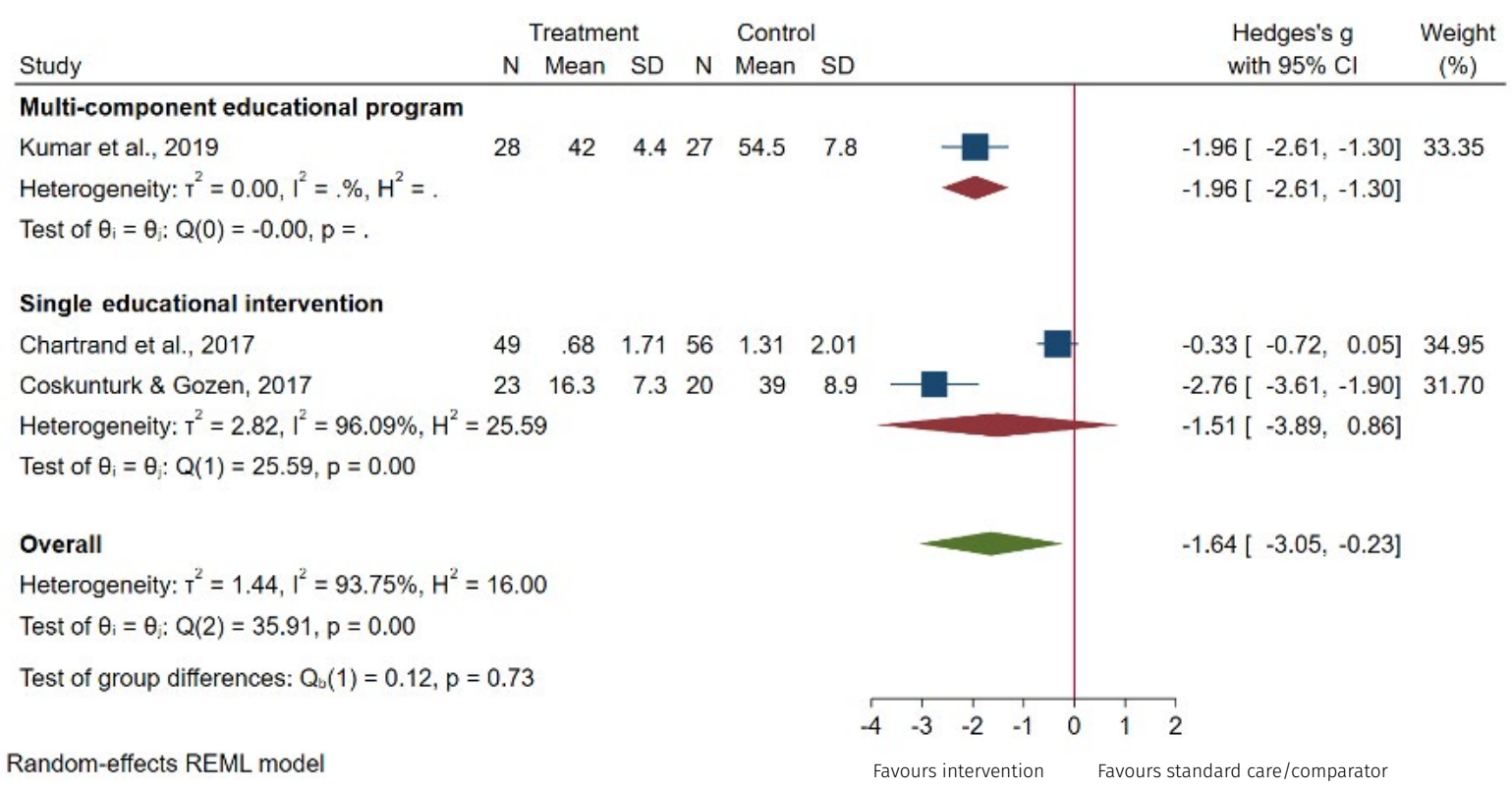

Figure 12: Post-operative parental anxiety

Forest plot showing effect sizes (Hedges' g) and 95\% confidence interval (Cl) with a pooled subgroup analysis (random-effects model) of the multi-component educational program and single educational intervention's studies. 


\section{Discussion}

This systematic review of 28 studies yielded a meta-analysis of 21 RCTS $^{40,54-59,61-68,71,75,78-80}$ with 1872 children and adolescents and nine RCTs $^{54,58,59,61,63,64,78,80}$ with 737 parents over three different outcomes: pain, anxiety and behaviours. To our knowledge, this is the first systematic review presenting an overview of the effect of family-centred educational interventions on children's/ adolescents' and parents' outcomes during the perioperative journey.

The results of our meta-analysis suggest that educational interventions can achieve a large reduction in perioperative paediatric anxiety levels, improve paediatric behaviours at induction of anaesthesia and reduce parental pre-operative and post-operative anxiety levels. These results are also supported by the findings of the studies not included in the metaanalysis.

We encountered several difficulties gathering information from the included studies to carry out metaanalyses. The high heterogeneity among the studies at different time points is noticeable and should be considered when judgements about the applicability of these findings in the perioperative context are made. For instance, two major challenges might be the subjective nature of these interventions and the small sample size. Furthermore, the included studies used different types of educational interventions, using video resources, video through virtual reality, games, DVDs, books, leaflets and therapeutic play. Finally, although all studies have used validated and reliable tools, the diverse range of measurement instruments employed and the low number of studies included did not allow us to explore each intervention's effectiveness independently. Considering this, a meta-analysis using a randomeffects model was performed to provide valuable information to guide perioperative teams in delivering their care.

Educational interventions effectively reduce pre-operative anxiety of children and adolescents undergoing elective surgery, with statistical differences between groups. This finding is supported by the experimental and quasi-experimental studies included in this review and reinforces the conclusion of the narrative synthesis developed by Copanitsanou and collaborators involving pre-operative education at the paediatric age. ${ }^{41}$ However, the moderate quality of evidence (downgraded for serious imprecision, inconsistency and publication bias) does not allow us to make conclusive inferences or recommendations for perioperative practice.

In addition, a systematic review studying the effects of audio-visual interventions on children's anxiety ${ }^{39}$ concluded that these effectively reduce children's perioperative anxiety. This finding was supported in the current review, where individual studies in which multimedia was used when educating children and adolescents reported a greater effect on pre-operative anxiety levels. ${ }^{56,58,69}$

In contrast to the findings reported by Kim et al. ${ }^{43}$ in which children benefited more from pre-operative technology-based preparation programs, our study found that children and adolescents who participated in a single educational intervention expressed lower pre-operative anxiety scores than those enrolled in a multi-component educational program. This is possibly related to the family-centredness and educational components of our study. Insufficient data on the paediatric population from the different studies did not allow us to stratify the results by age (children and adolescents). Although adolescents were included in the eligibility criteria of this review, only three of the 28 included studies had adolescents in their population sample, $40,64,72$ hence the need for more primary studies. ${ }^{81}$

Additionally, the findings from our review suggest that implementing educational interventions may be useful to increase paediatric compliance at induction of anaesthesia but not in reducing post-operative behavioural disturbances in children and adolescents. With only two relatively small studies, the estimate was not precise enough to determine the direction of effect; therefore, we are uncertain regarding the effectiveness of these interventions on children's and adolescents' post-operative maladaptive behaviours. Moreover, educational interventions do not seem to affect the incidence of emergence delirium symptoms in the recovery area.

In our narrative synthesis, children and adolescents benefited from educational interventions to reduce post-operative pain intensity without statistically significant differences. Evidence supports that children and adolescents with higher levels of anxiety prior to surgery tend to exhibit greater intensity of post-operative pain. ${ }^{82}$ However, only one study ${ }^{73}$ has reported a significant correlation between anxiety levels and pain intensity one week post-operatively.

Regarding parental anxiety, the results from this review suggest that the implementation of educational interventions might provide a valuable alternative to reduce parental anxiety, and this concurs with findings from the study conducted by Copanitsanou and collaborators. ${ }^{41}$ Multi-component educational programs, ${ }^{64,66}$ with 
pre-operative tours, pamphlets and booklets, were also associated with a greater reduction in pre-operative anxiety levels, corroborating the results of the systematic review undertaken by Kim and collaborators. ${ }^{43}$

\section{Strengths and limitations}

This systematic review and metaanalysis has multiple strengths, including a wide range of data collection from different databases and studies from various countries, which enhance generalisability to our results. However, we are aware that our research may have several limitations that contributed to the high heterogeneity of the overall results. We speculate that these limitations were linked with insufficient studies at specific evaluation time points and studied outcomes, small study sample sizes, the wide range of participants' ages, and differences in measurement instruments across the studies. In addition, no differentiation was made between 'self' and 'observed' assessments. Since we have included studies only written in English, Spanish and Portuguese, language bias was also present. In addition, we must assume as a limitation the lack of the terms 'disorders', 'sleeping' and 'eating' related to the post-operative maladaptive behaviours in our search strategy. Finally, this review did not explore the content and type of methodologies and materials used due to the lack of studies.

\section{Conclusions}

The findings from this systematic review provide further evidence to improve perioperative practice in paediatric settings, indicating the probable benefits of implementing family-centred educational interventions to reduce perioperative family anxiety and improve paediatric behaviours at induction of anaesthesia. However, the diversity of measurement instruments used among the studies makes performing a meta-analysis and producing more robust data difficult.

\section{Implications for practice}

Family-centred education can lead to reduced anxiety levels in children, adolescents and parents, and improved compliance at induction of anaesthesia, in comparison with standard or other preparation methods. Children and adolescents seem to benefit more from single educational interventions, whereas parents demonstrate better health outcomes with multi-component educational programs. Therefore, tailored family-centred education is essential to meet children's, adolescents' and parents' needs.

\section{Implications for future research}

This review has found possible benefits of educational interventions for the family at the different stages of the perioperative journey. If further comparative effectiveness trials aim to determine whether or not educational interventions are effective, these should consider a larger sample size. In addition, further studies with adolescents and parents are needed to understand the impact of educational interventions on the management of pain and anxiety during the perioperative journey.

\section{Note: This review will contribute towards a MSc in Paediatric Nursing for the first author, IE.}

\section{Competing interest}

The authors declare no conflict of interest.

\section{References}

1. Kain ZN, Mayes L, Caldwell-Andrews A, Karas D, McClain B. Preoperative anxiety, postoperative pain, and behavioral recovery in young children undergoing surgery. Pediatrics. 2006;118(2):651-8.

2. Perry JN, Hooper VD, Masiongale J. Reduction of preoperative anxiety in pediatric surgery patients using age-appropriate teaching interventions. J Perianesth Nurs. 2012;27(2):69-81.

3. Ayenew NT, Endalew NS, Agegnehu AF, Bizuneh YB. Prevalence and factors associated with preoperative parental anxiety among parents of children undergoing anesthesia and surgery: A cross-sectional study. Int J Surg Open. 2020;24(0):18-26.

4. Li HC, Lam H. Paediatric day surgery: Impact on Hong Kong Chinese children and their parents. J Clin Nurs. 2003;12(6):882-7.

5. Gabriel M, Wakefield C, Vetsch J, Karpelowsky J, Darlington A-S, Grant D et al. The psychosocial experiences and needs ofchildren undergoingsurgery and their parents: A systematic review. J Pediatr Health Care. 2018;32(2):134-49.

6. Fortier MA, Rosario A, Martin S, Kain ZN. Perioperative anxiety in children. Paediatr Anaesth. 2010;20(4):318-22.

7. International Federation of Perioperative Nurses (IFPN). Supporting perioperative nurses. Promoting safe surgery and evidence-based practice [Internet]. IFPN; 2021 [cited 2021 Aug 3]. Available from: https://www.ifpn.world

8. Al-Sagarat $\mathrm{A}, \mathrm{Al}$-Oran $\mathrm{H}$, Obeidat $\mathrm{H}$, Hamlan A, Lorna M. Preparing the family and children for surgery. Crit Care Nurs Q. 2017;40(2):99-107.

9. Charana A, Tripsianis G, Matziou V, Vaos G, Iatrou C, Chloropoulou P. Preoperative anxiety in Greek children and their parents when presenting for routine surgery. Anesthesiol Res Pract. 2018; 2018(0):5135203.

10. Chahal N, Manlhiot C, Colapinto K, Van Alphen J, McCrindle B, Rush J. Association between parental anxiety and compliance with preoperative requirements for pediatric outpatient surgery. Journal of Pediatric Health Care. 2009;23(6):372-7.

11. Kain ZN, Caldwell-Andrews A, Mayes L, Weinberg M, Wang S-M, MacLaren J et al. Family-centered preparation for surgery improves perioperative outcomes in children. Anesthesiology. 2007;106(1):65-74.

12. Agbayani C-J, Fortier MA, Kain ZN. Nonpharmacological methods of reducing perioperative anxiety in children. BJA Educ. 2020;20(12):424-30. 
13. Sadeghi A, Tabari A, Mahdavi S, Razavi S. Impact of parental presence during induction of anesthesia on anxiety level among pediatric patients and their parents: A randomized clinical trial. Neuropsychiatr Dis Treat. 2017;12(0):3237-41.

14. Fortier MA, Kain ZN. Treating perioperative anxiety and pain in children: A tailored and innovative approach. Paediatric Anaesth. 2015;25(1):27-35.

15. Kain ZN, Wang SM, Mayes L, Caramico L, Hofstadter M. Distress during the induction of anesthesia and postoperative behaviora outcomes. Anesth Analg. 1999;88(0):1042-7.

16. Cohen-Salmon D. Perioperative psychobehavioural changes in children. Ann Fr Anaesth Reanim. 2010;29(4):289-300.

17. Burstein M. The effect of parental modeling of anxious behaviors and cognitions in school-aged children: An experimental pilot study. Behav Res Ther. 2010;48(6):506-15.

18. Getahum AB, Endalew NS, Mersha A, Admass $B$. Magnitude and factors associated with preoperative anxiety among pediatric patients: Cross-sectional study. Pediatric Health Med Ther. 2020;11(0):485-94.

19. Esra Cagiran E, Sergin D, Deniz M, Tanattı B, Emiroglu N, Alper I. Effects of sociodemographic factors and maternal anxiety on preoperative anxiety in children. J Int Med Res. 2014;42(2):572-80.

20. Rice M, Glasper A, Keeton D, Spargo P. The effect of a preoperative education programme on perioperative anxiety in children: An observational study. Paediat Anaesth. 2008;18(5):426-30.

21. Simeone S, Pucciarelli G, Perrone M, Rea T, Gargiulo G, Dell'Angelo $G$ et al. Comparative analysis: implementation of a pre-operative educational intervention to decrease anxiety among parents of children with congenital heart disease. J Pediatr Nurs. 2017;35(2017):144-8.

22. Wright K, Stewart S, Finley G, Buffett-Jerrott S. Prevention and intervention strategies to alleviate preoperative anxiety in children: A critical review. Behav Modif. 2007;31(1):52-79.

23. Heikai S, Stuart G. Anxiolytic premedication for children. BJA Educ. 2020;20(7):220-5.

24. Tomaszek L, Fenikowski D, Maciejewski P, Komotajtys H, Gawron D. Perioperative gabapentin in pediatric thoracic surgery patients-randomized, placebo-controlled phase 4 trial. Pain Med. 2020;21(8):1562-71.

25. Cox RG, Nemish U, Ewen A, Crowe MJ. Evidence-based clinical update: Does premedication with oral midazolam lead to improved behavioural outcomes in children? 2006. In: Database of Abstracts of Reviews of Effects (DARE): Quality-assessed reviews [Internet]. York (UK): Centre for Reviews and Dissemination (UK); 2010 [cited $2021 \mathrm{Jul}$ 29]. Available from: www.ncbi.nlm.nih.gov/ books/NBK72871
26. Lee J-H, Jung H-K, Lee G-G, Kim H-K, Park S-G, Woo S-C. Effect of behavioral intervention using smartphone application for preoperative anxiety in pediatric patients. Korean J Anesthesiol. 2013;65(6):508-18.

27. Blake S. Supporting paediatric patients: Parental presence in the anaesthetic journey. J Perioper Nurs. 2019;32(4):27-32.

28. Heckmann M, Beauchesne M. Pediatric perioperative education current practices: A national survey of children's hospitals in the United States. J Perioper Pract. 2013;23(5):100-6.

29. Committee on Hospital Care IfP-aFCC. Patient- and family-centered care and the pediatrician's role. Pediatrics. 2012;129(2):394-404

30. Buckley A, Savage E. Meeting patient information needs: Preoperative information needs of children undergoing tonsillectomy. J Clin Nurs. 2010;19(0):2879-87.

31. Gordon BK, Bartlett K, Perrin M, Jackson A Sandstrom A, Charleston R et al. Child and parental surveys about pre-hospitalization information provision. Child Care Health Dev. 2010;37(5):727-33.

32. Heiss K, Raval MV. Patient engagement to enhance recovery for children undergoing surgery. Semin Pediatr Surg. 2018;27(0):86-91.

33. Buyuk E, Bolisik B. An analysis of the anxiety levels of mothers who participate in education and therapeutic games about their children's surgeries. J Perianesth Nurs. 2018;33(3):290-5.

34. Jaaniste $T$, Hayes $B$, von Baeyer C. Providing children with information about forthcoming medical procedures: A review and synthesis. Clin Psychol. 2007;14(2):124-43.

35. Bray L, Appleton V, Sharpe A. The information needs of children having clinical procedures in hospital: Will it hurt? Will feel scared? What can I do to stay calm? Child Care Health Dev. 2019;45(0):737-43.

36. He HG, Chan WCS, Liam JLW, Ko S, Li HCW. A mixed-method study of effects of a therapeutic play intervention for children on parental anxiety and parents' perceptions of the intervention. J Adv Nurs. 2015;71(7):153951.

37. Capurso M, Ragni B. Psycho-educational preparation of children for anaesthesia: A review of intervention methods. Patient Educ Couns. 2016:99(2016):173-85.

38. Fortier MA, Bunzli E, Walthall J, Olshansky E, Saadat H, Santistevan R et al. Web-based tailored intervention for preparation of parents and children for outpatient surgery (WebTIPS): Formative evaluation and randomized controlled trial. Anesth Analg. 2015;120(4):915-22.

39. Chow C, Lieshout R, Schmidt L, Dobson K, Buckley N. Systematic Review: Audiovisual interventions for reducing preoperative anxiety in children undergoing elective surgery. J Pediatr Psychol. 2016;41(2):182-203.
40. Zhu L, Chan WCS, Liam JLW, Xiao C, Lim ECC, Luo $\mathrm{N}$ et al. Effects of postoperative pain management educational interventions on the outcomes of parents and their children who underwent an inpatient elective surgery: A randomized controlled trial. J Adv Nurs. 2018;74(7):1517-30

41. Copanitsanou P, Valkeapaa K. Effects of education of paediatric patients undergoing elective surgical procedures on their anxiety - a systematic review. J Clin Nurs. 2013;23(0):940-54.

42. Dai Y, Livesley J. A mixed-methods systematic review of the effectiveness and acceptability of preoperative psychological preparation programmes to reduce paediatric preoperative anxiety in elective surgery. J Adv Nurs. 2018;2018 May 13.

43. Kim J, Chiesa N, Raazi M, Wright K. A systematic review of technology-based preoperative preparation interventions for child and parent anxiety. Can J Anaesth. 2019;66(8):966-86

44. He HG, Klainin-Yobas P. The effectiveness of therapeutic play intervention in reducing perioperative anxiety, negative behaviors, and postoperative pain in children undergoing elective surgery: A systematic review. Pain Manag Nurs. 2015;16(3):425-39.

45. Tufanaru C, Munn Z, Aromataris E, Campbell J, Hopp L. Chapter 3: Systematic reviews of effectiveness. In: JBI Manual for Evidence Synthesis [Internet]. Adelaide: JBI; 2021 [cited 2021 Jul 24]. Available from: synthesismanual.jbi.global/

46. Page M, McKenzie J, Bossuyt P, Boutron I, Hoffmann T, Mulrow $C$ et al. The PRISMA 2020 statement: An updated guideline for reporting systematic reviews. BMJ. 2021;372:n71.

47. Martins Esteves I, Pestana-Santos M, Coelho M, Reis Santos M. Effectiveness of familycentered educational interventions in the anxiety, pain and behaviors of children/ adolescents and their parents' anxiety in the perioperative period: Systematic review protocol (CDR42020211574) University of York: PROSPERO International prospective register of systematic reviews; 2020 [cited 2021 Jul 10]. Available from: www.crd.york.ac.uk/prospero/display_record php?!D=CRD42020211574

48. Brazio P. Child anxiety in surgical context: Experimental study. Madeira: University of Madeira; 2014.

49. StataCorp. Stata Statistical Software: Release 16. College Station, Texas 2019.

50. Hozo SP, Djulbegovic B, Hozo I. Estimating the mean and variance from the median, range, and the size of a sample. BMC Med Res Methodol. 2005;5(0):13.

51. Higgins J, Thompson S. Quantifying heterogeneity in a meta-analysis. Stat Med. 2002:21(11):1539-58. 
52. Egger M. Meta-analysis: Principles and procedures. BMJ. 1997;315:1533

53. Guyatt G, Oxman A, Vist G, Kunz R, Falck-Ytter $\mathrm{Y}$, Alonso-Coello $\mathrm{P}$ et al. GRADE: An emerging consensus on rating quality of evidence and strength of recommendations. BMJ. 2008;336(7650):924-6.

54. Chartrand J, Tourigny J, MacCormick J. The effect of an educational pre-operative DVD on parents' and children's outcomes after a same-day surgery: A randomized controlled trial. J Adv Nurs. 2017:73(3):599-611.

55. Ryu JH, Park SJ, Park JW, Kim JW, Yoo HJ, Kim TW et al. Randomized clinical trial of immersive virtual reality tour of the operating theatre in children before anaesthesia. BJS Open. 2017;104(12):1628-33.

56. Ryu JH, Park JW, Nahm FS, Jeon YT, Oh AY, Lee $\mathrm{HJ}$ et al. The effect of gamification through a virtual reality on preoperative anxiety in pediatric patients undergoing general anesthesia: A prospective, randomized, and controlled trial. J Clin Med. 2018;7(9)

57. Ryu JH, Oh AY, Yoo HJ, Kim JH, Park JW, Han $\mathrm{SH}$. The effect of an immersive virtual reality tour of the operating theater on emergence delirium in children undergoing general anesthesia: A randomized controlled trial. Paediatr Anaesth. 2019:29(1):98-105.

58. Park JW, Nahm FS, Kim JH, Jeon YT, Ryu JH, Han $\mathrm{SH}$. The effect of mirroring display of virtual reality tour of the operating theatre on preoperative anxiety: A randomized controlled trial. IEEE J Biomed Health Inform. 2019;23(6):2655-60.

59. Coskunturk AE, Gozen D. The effect of interactive therapeutic play education program on anxiety levels of children undergoing cardiac surgery and their mothers. J Perianesth Nurs. 2018;33(6):781-9.

60. Bartik K, Toruner EK. Effectiveness of a preoperative preparation program on children's emotional states and parental anxiety. J Perianesth Nurs. 2018;33(6):972-80.

61. Bumin Aydın G, Sakızcı Uyar B. Mothers' level of education and preoperative informative story book reading helps reduce preoperative anxiety in children in Turkey. J Pediatr Nurs. 2021

62. Batuman A, Gulec E, Turktan M, Gunes Y, Ozcengiz D. Preoperative informational video reduces preoperative anxiety and postoperative negative behavioral changes in children. Minerva Anestesiol. 2016;82(5):534-42.

63. Yadav M, Malar Kodi S, Deol R. Effect of preoperative educational schedule on anxiety and coping mechanism among children and their parents: A randomized controlled trial. J Pediatr Surg Nurs. 2020;9(4):127-35.
64. Kumar A, Das S, Chauhan S, Kiran U, Satapathy S. Perioperative anxiety and stress in children undergoing congenital cardiac surgery and their parents - effect of brief intervention: A randomized control trial. J Cardiothorac Vasc Anesth. 2019;33(5):1244-50.

65. Faramarzi M, Roosta S, Faramarzi A, Salehi A, Matani N. The effectiveness of a preoperative multi-component non-pharmacologic preparation on post-tonsillectomy pain: A randomized controlled clinical trial. Int J Pediatr Otorhinolaryngol. 2020;138:110359.

66. Tabrizi JS, Seyedhejazi M, Fakhari A, Ghadim F, Hamidi M, Taghizadieh N. Preoperative education and decreasing preoperative anxiety among children aged 8-10 years old and their mothers. Anesth Pain Med. 2015;5(4):e25036.

67. Vaezzadeh N, Douki Z, Hadipour A, Osia S, Shahmohammadi S, Sadeghi R. The effect of performing preoperative preparation program on school age children's anxiety. Iran J Pediatr. 2011;21(4):461-6.

68. Fincher W, Shaw J, Ramelet A-S. The effectiveness of a standardised preoperative preparation in reducing child and parent anxiety: A single-blind randomised controlled trial. J Clin Nurs. 2012;21(7-8):94655.

69. Liguori S, Stacchini M, Ciofi D, Olivini N Bisogni S, Festini F. Effectiveness of an app for reducing preoperative anxiety in children: A randomized clinical trial. JAMA Pediatr. 2016;170(8):e160533.

70. Lin C-J, Liu H-P, Wang P-Y, Yu M-H, Lu $M-C$, Hsieh L-Y et al. The effectiveness of preoperative preparation for improving perioperative outcomes in children and caregivers. Behav Modif. 2019;43(3):311-29.

71. LI HCW, Lopez V, Lee TLI. Effects of preoperative therapeutic play on outcomes of school-age children undergoing day surgery. Res Nurs Health. 2007;30(3):320-32.

72. Kassai B, Rabilloud M, Dantony E, Grousson S, Revol O, Malik S et al. Introduction of a paediatric anaesthesia comic information leaflet reduced preoperative anxiety in children. BJA Open. 2016;117(1):95-102.

73. Matthyssens LE, Vanhulle A, Seldenslach L, Vander Stichele G, Coppens M, Van Hoecke $E$. A pilot study of the effectiveness of a serious game CliniPup ${ }^{\circledR}$ on perioperative anxiety and pain in children. J Pediatr Surg. 2020:55(2):304-11.

74. Fernandes SC, Arriaga P, Esteves F. Providing preoperative information for children undergoing surgery: A randomized study testing different types of educational material to reduce children's preoperative worries. Health Educ Res. 2014;29(6):1058-76.

75. Fernandes S, Arriaga P, Esteves F. Using an educational multimedia application to prepare children for outpatient surgeries. Health Commun. 2015;30(12):1190-200.
76. Wakimizu R, Kamagata S, Kuwabara T, Kamibeppu K. A randomized controlled trial of an at-home preparation programme for Japanese preschool children: Effects on children's and caregivers' anxiety associated with surgery. J Eval Clin Pract. 2009;15(2):393401.

77. Sabaq A, El-Awady S. The effect of pre-operative preparation program and mothers presence during induction on anxiety level and behavior change in young children undergoing elective surgery. Life Sci J. 2012:9(4):3798-807

78. Cumino DO, Cagno G, Gonçalves VF, Wajman DS, Mathias LA. Impact of preanesthetic information on anxiety of parents and children. Braz J Anesthesiol. 2013;63(6):47382.

79. Cumino DO, Vieira JE, Lima LC, Stievano LP, Silva RA, Mathias LA. Smartphonebased behavioural intervention alleviates children's anxiety during anaesthesia induction: A randomised controlled trial. Eur J Anaesthesiol. 2017;34(3):169-75.

80. Eijlers R, Dierckx B, Staals LM, Berghmans JM, van der Schroeff MP, Strabbing EM et al. Virtual reality exposure before elective day care surgery to reduce anxiety and pain in children: A randomised controlled trial. Eur J Anaesthesiol. 2019;36(10):728-37.

81. Pestana-Santos M, Pereira MJ, PestanaSantos A, Santos E, Gonçalves A, Cardoso D et al. Effectiveness of non-pharmacological interventions to manage anxiety in adolescents in the perioperative period: $\mathrm{A}$ systematic review and meta-analysis. JPN. 2021;34(3):e-15-e-25

82. Chieng Y, Chan WCS, Klainin-Yobas P, He HG Perioperative anxiety and postoperative pain in children and adolescents undergoing elective surgical procedures: A quantitative systematic review. J Adv Nurs. 2014;70(2):24355. 